\title{
Assessing climate and human activity effects on lake characteristics using spatio-temporal satellite data and an emotional neural network
}

\author{
Alireza Mojtahedi ( $\sim$ a.mojtahed@tabrizu.ac.ir) \\ University of Tabriz \\ Mehran Dadashzadeh \\ University of Tabriz \\ Mostafa Azizkhani \\ Kerman Graduate University of Technology: Graduate University of Advanced Technology \\ Abdolmajid Mohammadian \\ University of Ottawa \\ Ramin Almasi \\ University of Tabriz
}

\section{Research Article}

Keywords: Spatio-temporal analysis, Remote sensing, Emotional Artificial Neural Networks, Climate Change, Anthropogenic

Posted Date: August 4th, 2021

DOl: https://doi.org/10.21203/rs.3.rs-258482/v1

License: (c) (1) This work is licensed under a Creative Commons Attribution 4.0 International License.

Read Full License

Version of Record: A version of this preprint was published at Environmental Earth Sciences on January 20th, 2022. See the published version at https://doi.org/10.1007/s12665-022-10185-3. 
Assessing climate and human activity effects on lake characteristics using spatio-temporal satellite data and an emotional neural network

Alireza Mojtahedi ${ }^{*}$, a, Mehran Dadashzadeh ${ }^{\mathrm{b}}$, Mostafa Azizkhani ${ }^{\mathrm{c}}$, Abdolmajid Mohammadian ${ }^{\mathrm{d}}$, Ramin Almasi $\mathrm{i}^{\mathrm{e}}$

${ }^{a}$ Associated Professor, Faculty of Civil Engineering, University of Tabriz, Iran. a.,mojtahed@tabrizu.ac.ir (author for correspondence)

${ }^{b}$ PhD candidate, Faculty of Civil Engineering, University of Tabriz, Iran.

${ }^{c}$ GIS Engineering, Civil and Surveying Engineering Department, Graduate University of Advanced Technology, Iran

${ }^{d}$ Associated Professor, Faculty of Engineering, University of Ottawa, Canada

${ }^{e}$ Faculty of Civil Engineering, University of Tabriz, Iran.

\begin{abstract}
Different sensing methods provide valuable information for comprehensive monitoring strategies, which are crucial for the ecological management of lakes and watersheds. Subsequently, the resulting spatio-temporal information can be considered the fundamental knowledge for the water resources management of watersheds. Lake Urmia is deemed one of the most important aquatic habitats in Iran. It has been experiencing significant changes during recent years due to climate change, anthropogenic activities, and a lack of coherent management approaches. Hence, awareness of the hydro-ecological factors during the last few decades is critical for identifying the problems. In this research, the impacts of changes in key parameters such as precipitation, evapotranspiration, water surface temperatures, suspended sediment concentration, saline features, and vegetation are explored using satellite imagery. The primary purpose of this study is to evaluate the Lake Urmia crisis concerning humaninvolved and climate factors such as the agriculture sector and construction of the causeway. In this regard, a limbic based Emotional Artificial Neural Network (EANN) is developed as a non-linear universal mapping and implemented for the first time to demonstrate the interactions between the considered hydro-ecological factors and the sensitivity of the two indicators the lake health. Providing a comprehensive spatio-temporal analysis is another objective of this study in order to detect the onset of deterioration in the parameters. The values of the efficiency criteria were measured to evaluate the sensitivity of the EANN models to the related inputs. The quantitative results confirm that the combination of both climate and anthropogenic factors, including the agricultural sector's overdraft, leads to the most efficient EANN model and, consequently, is considered the leading cause of the crisis.
\end{abstract}

Keywords: Spatio-temporal analysis; Remote sensing; Emotional Artificial Neural Networks; Climate Change; Anthropogenic

\title{
1. Introduction
}

Lake Urmia is one of the largest hyper-saline lakes globally, with considerable ecological, environmental, and cultural value. It is located in an endorheic watershed in northwest Iran $\left(37^{\circ} 4^{\prime}-38^{\circ} 17^{\prime} \mathrm{N}\right.$ and $\left.45^{\circ}-46^{\circ} \mathrm{E}\right)$. The lake was registered under the Ramsar Convention as an area of international importance for birds and a unique brine shrimp species, Artemia urmiana. The lake watershed is an important agricultural region with a population of around 5 million people.

Over recent years, the lake's surface area and water level have been declining (Afzali 2020; Maleki 2019). The decline is generally can be attributed to different factors, including climate change, increased water diversion for irrigated agriculture within the lake's watershed, and mismanagement (AghaKouchak et al. 2014; Eimanifar and Mohebbi 2007; Hassanzadeh et al. 2011; Hosseinpour et al. 2010; Khatami 2013; Okhravi et al. 2017). The land subsidence due to changes in groundwater reservoirs is detected and analyzed in several studies (Ghorbanzadeh 2018; Moghtased-Azar 2012; Amirataee et al. 2016). Also, a causeway has been built across the lake with a narrow gap, which may decrease the water circulation between the northern and southern halves of the lake. While in the last 50 years, the lake's average altitude and area were recorded at about $1274 \mathrm{~m}$ and $5300 \mathrm{~km}^{2}$, respectively, in recent years, they have been estimated at less than $1271 \mathrm{~m}$ and $2500 \mathrm{~km}^{2}$ (IWPMC, 2015). Fig. 1 shows the changes in the surface area of the Lake Urmia using Landsat imagery green, red and Near-infrared (NIR) bands between 2005 to 2014 . 

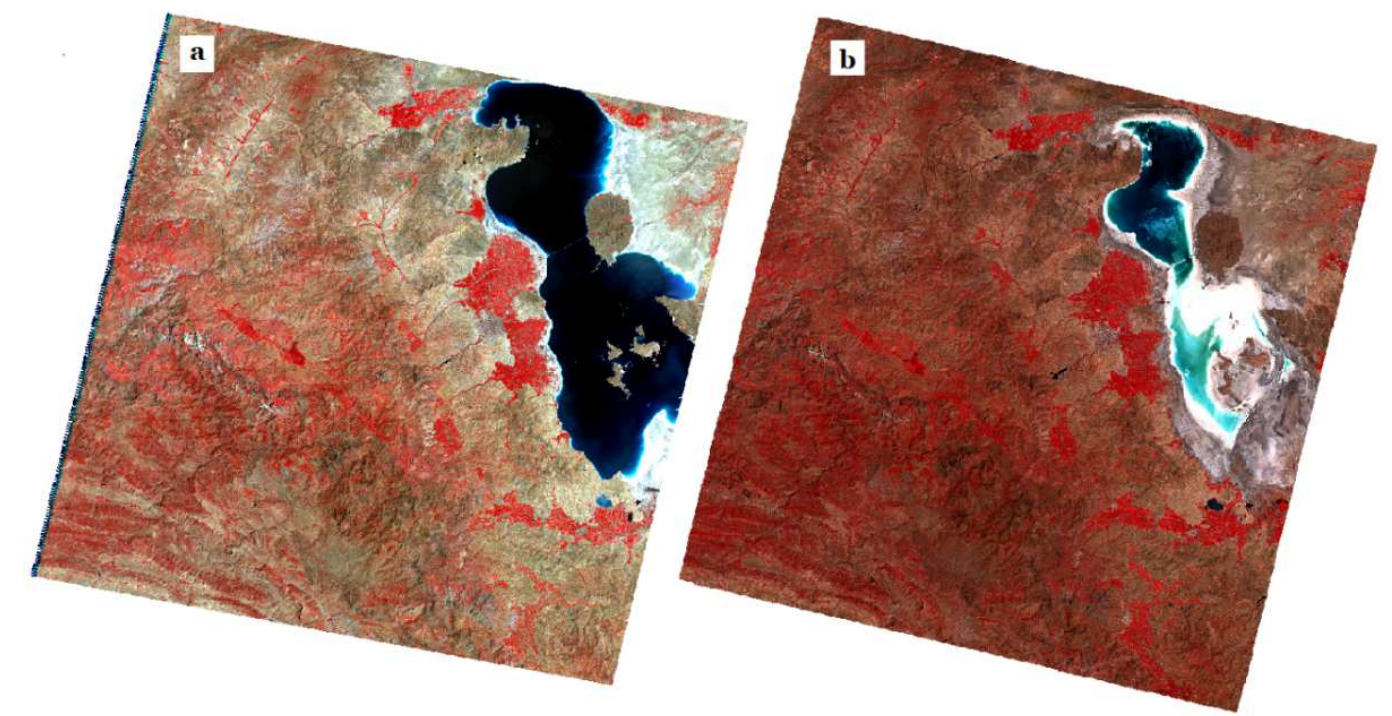

Fig. 1 Lake Urmia surface area change using Landsat imagery band 3, 4, and 5, a) 19.Jul.2005 and b) 20.Jul 2014

During the recent 17-year period, the Landsat satellite dataset illustrates the water retrogradation and the expansion of saline features around the lake. More lakebed and salt will be exposed as the surface water continues to shrink(Garousi et al., 2013; Sekertekin, 2020). Of the severe salinization effects, one can mention the ecological threats caused by the lake bed turning into a salt-covered wasteland and the consequent soil erosion (Pitman and Läuchli 2002).

Scientists have warned that the continuation of the reduction in water volume will lead to the collapse of the lake's ecosystem and salt storms, negatively impacting the regional environment and health (Azarnivand et al., 2015). Besides, the simultaneous increases in the lake's watershed and surface water temperatures have led to the rise in the water requirements for plants and the evaporation rate of the water's surface, which exacerbates the crisis (Barzegar et al. 2019).

Considering the importance of the problem, a detailed and comprehensive analysis of the changes in dominant parameters is essential for the control and management of the lake, and the evaluation and implementation of effective restoration methods require appropriate spatial data analysis. Therefore, remote sensing methods can provide valuable spatial data to conduct a comprehensive monitoring strategy essential for ecological management.

Several studies have been carried using satellite imagery and remote sensing technologies to develop monitoring procedures for the lake in recent years.

Alavipanah et al. (2005) studied the effects of the causeway on water quality changes, including chemical, physical, and biological properties, using remote sensing procedures. The results showed that both reflective and thermal bands have great potential for detecting the effects of turbidity and salinity.

Jaafari et al. (2013) examined the changes in the Lake Urmia area by using Landsat satellite imagery and GIS methods. Using satellite images of Landsat from 1990, 1998, 2006, and 2011 and a land-use map, they concluded that the water area of the lake has decreased by $3052 \mathrm{~km}^{2}$ over the mentioned period. Mitchell (2013) used remote sensing technology and Landsat 5 (1990, 1998, and 2006) and Landsat 8 (2013) satellite imagery with intervals of 8 years for the period 1990 to 2013 in order to study changes in the water area and saline features of Lake Urmia. This study shows an increase in the water, saline features, and vegetation areas between 1990 to 1998. The results illustrate that the water area had decreased from $4,995 \mathrm{~km}^{2}$ to $1,849 \mathrm{~km}^{2}$, and the saline features had increased by $898 \mathrm{~km}^{2}$ from 1998 to 2013 . Khademi et al. (2014) studied the saline features around the lake using Landsat satellite imagery, remote sensing, and spatial analysis. The study of Landsat satellite images over 13 years illustrated a very rapid increase in saline features and that the area of salt marsh in 2011 was approximately 26 times that of 1998. Komaki (2014) studied the changes in the water area of Lake Urmia using Operational Land Imager (OLI), Thematic Mapper (TM), and Multispectral Scanner (MSS) sensors from Landsat 8, 5, and 2, respectively. In addition, he used Google's image dataset in this study. Following the course of 38 years (from 1975 to 2013), in addition to a decrease of more than 60 per cent of the lake's area, it became apparent that changes in the spectral symptoms associated with saline features were detectable along the causeway. Alizade Govarchin Ghale et al. (2018) investigated the water budget of Lake Urmia and the intensity of drought in the watershed 
using Landsat satellite images. They concluded that anthropogenic impacts on the drying of the lake are more important than climate factors. Chaudhari et al. (2018) studied the natural and human-induced changes in the hydrology of the Lake Urmia watershed based on remote sensing data, ground observations, and a hydrological model. The results indicated that the reduction in lake volume is primarily due to direct anthropogenic alterations. Khazaei et al. (2019) studied hydro-climatic and vegetation changes in the Lake Urmia watershed using classical exploratory statistical methods. They concluded that the agricultural increase of vegetation cover in the watershed correlates well with the lake water level change, indicating this irrigation expansion as the dominant humaninduced reason for lake desiccation.

The changes in the climate of Lake Urmia might have consequences affecting people's health by phenomena such as windblown salt-storms (Dariane, 2019). The population surrounding Lake Urmia might be faced with many significant challenges. Following the continuous drying process of the lake, special commitment and attention were given by the Iranian government, leading to the establishment of a national governmental committee for Lake Urmia in 2013 called the Lake Urmia Restoration National Committee (LURNC).

This study aims to provide a spatio-temporal analysis to detect the onset of deterioration in the effective parameters to address the problem. Various factors have been mentioned which affect the crisis. In general, scientists believe that a combination of drought, climate change, increased water diversion for irrigated agriculture within the lake's watershed, mismanagement, and the constructed causeway are the most important causes of the lake's decline (Abbaspour et al. 2012; Faramarzi 2012; Kabiri et al. 2012; Karbassi et al. 2010; Shadkam et al. 2016). The relationship between the lake crisis and hydrological drought and anthropogenic factors is always a challenging problem. The residents and NGOs often believe in the imprint of human activity mismanagement as the primary cause. On the other hand, governmental organizations mostly blame climate change, noting the hierarchy in planning and making final decisions. However, there are not yet enough detailed studies on spatio-temporal analysis to conclude that anthropogenic and climate factors are the leading cause of the crisis (Shadkam et al. 2016). This study attempts to monitor the situation by exploring the impact of key features such as the water surface precipitation, evapotranspiration, water temperature, salinity, and vegetation via satellite imagery. For this purpose, this work aims to propose a novel framework for the sensitivity analysis of the interactions between dominant factors (including both human-involved and climate factors) and the indices of lake health using a robust artificial intelligence (AI) modelling technique. The reduction in Water Level (WL), the increases in the Sea Surface Temperature (SST) and the simultaneous rise in evaporation rate will lead to the collapse of the lake's ecosystem and exacerbates the crisis (Barzegar et al. 2019). Accordingly, these parameters were considered as the health indicators of the studied lake. The use of AI modelling strategies has increased more recently, with the recognition of their potential. They imitate human recognition learning and reasoning to solve complex problems and develop non-linear relationships to explain the complexity within several data sets without dealing with complicated deterministic non-linear mathematics. Therefore, AI models have become remarkably more suitable for modelling the processes within complex environmental systems (Chen et al. 2008).

Furthermore, they can generalize the input-output relationship considering the uncertainties associated with ambiguity and impreciseness due to the lack of information for the system. In this regard, an EANN model is developed and implemented for this work as an effective, fast, efficient and well-known methodology. The literature survey shows that while the EANN modelling is in the early stages, scientists are eagerly working to improve and extend its engineering applications (Abdi et al., 2012). To the best of the author's knowledge, this study is the first application of EANN to investigate the sensitivity of the recognized anthropogenic factors (including effects of the causeway on the saline features and agriculture sector) and the climate factors to the lake crisis. Several models are defined in section 3.2 to find the link between different hydro-ecological variables as the inputs of the EANN model and with health indicators, including SST and WL, as the model's output. The results of the measured efficiency criteria of the EANN models are used to interpret the influential parameters.

\section{Materials and methods}

In this study, first, a spatio-temporal analysis is performed from 2005 to 2015 (however, due to the availability of data, this period is extended from 1995 to 2016, like analyzing on changes in water surface area) obtained from Landsat and MODIS satellite images integrated into a Geographical Information System (GIS) analysis. All the satellite imagery data are obtained from the United States Geological Survey (USGS) satellite image dataset (EarthExplorer), NASA's Earth Observing System Data and Information System (EOSDIS), and the Center for Hydrometeorology and Remote Sensing (CHRS). The ArcGIS Desktop 10.3 package is used to calibrate, analyze, visualize, and characterize the recorded images for decision-making support.

Then, an AI modelling technique is implemented based on the concepts of the EANN modelling to evaluate the rate of correlation between the input parameters and the sensitivity of the considered indicators of the lake health 
indices (SST and WL), using the efficiency criteria. There is a consensus between scientists that the continuation of the reduction in water volume and, consequently, in WL may lead to the collapse of the lake's ecosystem. The simultaneous increases in the SST will cause a rise in the water requirements for plants and the evaporation rate, which exacerbates the crisis. Accordingly, these parameters were considered as the health indicators of the studied lake. In this regard, the spatio-temporal analysis is also performed to obtain the required results from 2015 to 2018. This period was chosen as the best to conclude on major factors of the leading cause of the crisis, considering the duration of decline in the lake's surface area and water level and simultaneous increases in the water temperatures of the lake's watershed and surface.

\subsection{Spatio-temporal analysis}

2.1.1. Detection of changes in vegetation cover and water surface area

Vegetation cover area, particularly cultivated vegetation, is one of the most important factors that may significantly affect the watershed. This study uses the MODIS land cover (MCD12Q1 and MCD12C1) product (Sulla-Menashe 2018). This product has 500-meter spatial resolution, which covers global with annual time steps. Detailed information regarding this product's accuracy and methodology is available in (Sulla-Menashe 2018). This product dataset is included five different types of classification, International Geosphere-Biosphere Programme (IGBP) classification with 18 classes, University of Maryland (UMD) classification with 16 classes, Leaf Area Index (LAI) classification with 12 classes, BIOME-Biogeochemical Cycles (BGC) classification with 9 classes, and Plant Functional Types (PFT) classification with 12 classes. In the current study, PFT classification has been performed. In table 1, the name, value, and description of PFT classification can be seen.

Table 1. the name, value, and description of PFT classification (Sulla-Menashe 2018).

\begin{tabular}{|c|c|c|}
\hline Name & Value & Description \\
\hline Water Bodies & 0 & At least $60 \%$ of the area is covered by permanent water bodies. \\
\hline $\begin{array}{c}\text { Evergreen } \\
\text { Needleleaf Trees }\end{array}$ & 1 & Dominated by evergreen conifer trees $(>2 \mathrm{~m})$. Tree cover $>10 \%$. \\
\hline $\begin{array}{l}\text { Evergreen Broadleaf } \\
\text { Trees }\end{array}$ & 2 & $\begin{array}{l}\text { Dominated by evergreen broadleaf and palmate trees }(>2 \mathrm{~m}) \text {. Tree } \\
\text { cover }>10 \% .\end{array}$ \\
\hline $\begin{array}{l}\text { Deciduous } \\
\text { Needleleaf Trees }\end{array}$ & 3 & $\begin{array}{l}\text { Dominated by deciduous needle leaf (larch) trees }(>2 \mathrm{~m}) \text {. Tree cover } \\
\qquad>10 \% .\end{array}$ \\
\hline $\begin{array}{l}\text { Deciduous Broadleaf } \\
\text { Trees }\end{array}$ & 4 & Dominated by deciduous broadleaf trees $(>2 \mathrm{~m})$. Tree cover $>10 \%$. \\
\hline Shrub & 5 & Shrub $(1-2 \mathrm{~m})$ cover $>10 \%$. \\
\hline Grass & 6 & Dominated by herbaceous annuals $(<2 \mathrm{~m})$ that are not cultivated \\
\hline Cereal Croplands & 7 & $\begin{array}{c}\text { Dominated by herbaceous annuals }(<2 \mathrm{~m}) \text {, at least } 60 \% \text { cultivated } \\
\text { cereal crops. }\end{array}$ \\
\hline Broadleaf Croplands & 8 & $\begin{array}{c}\text { Dominated by herbaceous annuals }(<2 \mathrm{~m}) \text {. At least } 60 \% \text { cultivated } \\
\text { broadleaf crops. }\end{array}$ \\
\hline $\begin{array}{l}\text { Urban and Built-up } \\
\text { Lands }\end{array}$ & 9 & $\begin{array}{c}\text { At least } 30 \% \text { impervious surface area including building materials, } \\
\text { asphalt, and vehicles. }\end{array}$ \\
\hline $\begin{array}{l}\text { Permanent Snow and } \\
\text { Ice }\end{array}$ & 10 & $\begin{array}{l}\text { At least } 60 \% \text { of the area is covered by snow and ice for at least } 10 \\
\text { months of the year. }\end{array}$ \\
\hline Barren & 11 & $\begin{array}{c}\text { At least } 60 \% \text { of the area is non-vegetated barren (sand, rock, soil) } \\
\text { with less than } 10 \% \text { vegetation. }\end{array}$ \\
\hline Unclassified & 255 & Has not received a map label because of missing inputs. \\
\hline
\end{tabular}

2.1.2. Spatio-temporal analysis of changes in evapotranspiration and precipitation

This study analyzes the changes in precipitation as the most important water inputs into the Lake Urmia watershed and Evapotranspiration (ET) as one of the significant outputs of the Lake Urmia. Lake Urmia watershed is an endorheic watershed, and Lake Urmia is located inside this watershed (Ansari 2020). Therefore, the spatiotemporal analysis of the changes in evapotranspiration and precipitation throughout this watershed would better understand the causes of decreases in the lake's water (Hesami 2016).

Precipitation data is derived from the CHRS data portal. The Precipitation Estimation from Remotely Sensed Information using Artificial Neural Networks (PERSIANN), and PERSIANN-Climate Data Record (CDR), which both are CHRS's datasets, are used for spatio-temporal analysis of precipitation (Nguyen 2019). PERSIANN utilizes long-wave (IR) images from geostationary orbiting (GEO) satellites to estimate the cloud-top temperature and low Earth-orbiting (LEO) satellites to estimate the bias correction. Machine Learning (ML) techniques 
determined precipitation using cloud-top temperature and bias correction. Detailed information regarding this CHRS accuracy and methodology is available in (Nguyen 2019).

MODIS (MYD16A3) 500-meter pixel resolution product for yearly ET is used to monitor changes in ET. ET can be used to monitoring regional water balance, soil water. Moreover, it provides critical information for water resource management. Long-run ET information offers a unique tool for analyzing the impact of climate change on land cover, ecosystems, and regional water resources. This product utilizes the Penman-Monteith equation, daily meteorological reanalysis data, and several MODIS products such as vegetation property dynamics, albedo, and land cover (Running 2017). Detailed information regarding this ET product accuracy and methodology is available in (Running 2017). (Running et al. 2019) used 46 field-based eddy covariance flux towers for validating the MYD16A3 product algorithm between 2000 to 2010. The study results show that the average Mean Absolute Errors (MAE) are $0.33 \mathrm{~kg} / \mathrm{m} 2 /$ day.

\subsubsection{Causeway impacts on the Lake Urmia}

A $1.25 \mathrm{~km}$-long dike-type causeway has been built across the lake to provide road access between the western and eastern provinces and divides the lake into northern and southern watersheds. They claim that the causeway's construction has led to a disruption in the lake's balance and degradation of its rich ecosystem due to lack of water flow (Karbassi et al. 2010; Zeinoddini et al. 2009). In this study, the effects of the causeway's construction are investigated by evaluating the changes in the saline features and the water surface temperature, as described in the following sections.

\section{Analysis of changes in suspended sediment concentration}

The robustness of remote sensing techniques is their ability to provide spatial and temporal views of suspended sediment concentration (SSC) that is usually not possible from in-situ measurements. Satellite observations from one time period need to be aligned to be compared and used to identify areas and changes. Reflectance, radiance, and atmospheric conditions affect the Digital Number (DN) values of satellite data. Radiometric calibration employs algorithms and processes that improve these data. The calibration is needed because the appearance of the same image varies with the angle of view and illumination conditions. Radiometric calibration of Landsat 8 is a two-step process. First, the DN values are converted using radiance conversion to at-satellite radiance using parameters provided in the image metadata. Second, data on solar intensity are used to convert the at-satellite radiance to at-satellite reflectance using reflectance conversion. These conversions are carried out using equations 1 and 2, respectively (Goslee 2011; Elsharkawy et al. 2012).

$$
\begin{aligned}
& L_{\lambda}=\text { Gain } \times D N+\text { Bias } \\
& \rho_{\lambda}=\frac{\pi L_{\lambda} d^{2}}{E S U N_{\lambda} \cdot \cos \theta_{s}}
\end{aligned}
$$

where Gain and Bias represent values related to a specific image band; $L_{\lambda}$ is at-satellite spectral radiance; $\rho_{\lambda}$ is unitless planetary reflectance at the satellite; $d$ is the Earth-Sun distance in astronomical units; $E S U N_{\lambda}$ is mean solar exoatmospheric irradiance; and $\theta_{s}$ is sun zenith angle which can be derived from the image metadata.

The research uses Landsat 8 satellite imagery to study changes in the SSC of Lake Urmia from 2000 to 2015. The images were calibrated using the expressed equations, and the Lake Urmia watershed boundary is determined from the 1999 image. Due to the large size of the Landsat imagery in the entire scene and to reduce computational volume, all images were masked using this boundary of the watershed, and areas outside the boundary are removed using ArcGIS Desktop 10.3 and "Extract by Mask". Also, to quantify the SSC, the water boundary of each year should be determined, and saline features should be removed. In this regard, the supervised classification was applied to the images using the Support Vector Machine (SVM) algorithm. SVM uses the kernel trick technique to transform the data. In the next step, SVM finds the best boundary between the possible outputs based on these transformations. The method of research uses three types of spectral transformation for suspended sediment is Normalized Suspended Material Index (NSMI), Normalized Differences Suspended Sediment Index (NDSSI), and Band Ratio (BR).

The NSMI index is developed on the basis that the pure water has maximum reflectance in the blue band, while the presence of suspended solids in water increases its reflectance throughout the visible spectrum, especially in the green and red bands $\left(\rho_{\text {red }}+\rho_{\text {green }}\right)$ (Equation 3). The resulting range on the NSMI index is between -1 to +1 , and the lower the value, the more precise the water. Research has shown that Landsat images are more sensitive to transparency in blue and near-infrared bands. NDSSI exploits band delimitation between near-infrared and blue ones (Equation 4). This index is also between -1 and +1 , with higher values indicating cleaner water (Hossain et al. 2010; Arisanty and Saputra 2017). 


$$
\begin{aligned}
& \text { NSMI }=\frac{\rho_{\text {red }}+\rho_{\text {green }}-\rho_{\text {blue }}}{\rho_{\text {red }}+\rho_{\text {green }}+\rho_{\text {blue }}} \\
& \text { NDSSI }=\frac{\rho_{\text {blue }}-\rho_{\text {NIR }}}{\rho_{\text {blue }}+\rho_{\text {NIR }}}
\end{aligned}
$$

The presence of suspended sediment in the water increases the reflectance in the green band range of the visible spectrum, while this reflection rises in the blue one range for pure water. The band ratio exerts green and blue bands to estimate suspended matter content (Equation 5). The result of this index ranges from 0 to infinity (Montalvo 2010).

$$
\text { Band Ratio }=\frac{\rho_{\text {green }}}{\rho_{\text {blue }}}
$$

\section{Analyzing of changes in saline features}

Lake Urmia is characteristically a hypersaline lake, with salinity measured at levels higher than 300g/L (Saemian 2020). Satellite remotely sensed imagery of land affected by salinity had been successfully done through the use of both multispectral and hyperspectral imagery. Imagery data acquired from Landsat TM has been effectively interpreted for salinity identification studies and is the most common type of imagery cited in numerous publications (Mohebzadeh 2019). Researchers have identified how essential thermal bands and infrared spectra help detect and mapping topographies and geological units such as saline lands (Ansari 2020). They have discriminated against the land units based on a single thematic mapper scene that seemed suitable to determine (Fazel 2016). In this study, Iso-cluster unsupervised classification is performed, and then the classes are labeled using field visits (Temko 2009). When setting a land cover map, it was necessary to take many GPS points of different features (Hesami 2016). In this work, points such as samples of saline fields around the lake were located and marked by a Garmin 62 GPS. The sample points are scattered in the different parts of the lake (in the north and the south of the causeway) with various water depths. Besides, GPS points were taken at locations like road crossings. To help create a coordinate system and for geo-referencing. The coordinates of the 16 points related to the collected samples are given in Table 2. The location of the points is also shown in Fig. 2. Cloud-free images captured during the period of the fieldwork were ordered. After classifying the images, they were used to determine salinity ranges around the causeway and lake.

Table 2. Coordinates of some of the sampled points used for classifications of salinity

\begin{tabular}{ccc}
\hline $\begin{array}{c}\text { Points } \\
\text { No. }\end{array}$ & Latitude & Longitude \\
\hline Sh1 & $37^{\circ} 47^{\prime} 47.40^{\prime \prime} \mathrm{N}$ & $45^{\circ} 22^{\prime} 51.60^{\prime \prime} \mathrm{E}$ \\
Sh2 & $37^{\circ} 47^{\prime} 50.00^{\prime \prime} \mathrm{N}$ & $45^{\circ} 22^{\prime} 54.10^{\prime \prime} \mathrm{E}$ \\
Sh3 & $37^{\circ} 47^{\prime} 52.50^{\prime \prime} \mathrm{N}$ & $45^{\circ} 23^{\prime} 1.70^{\prime \prime} \mathrm{E}$ \\
Sh4 & $37^{\circ} 47^{\prime} 54.20^{\prime \prime} \mathrm{N}$ & $45^{\circ} 23^{\prime} 4.50^{\prime \prime} \mathrm{E}$ \\
Sh5 & $37^{\circ} 47^{\prime} 56.90^{\prime \prime} \mathrm{N}$ & $45^{\circ} 23^{\prime} 8.60^{\prime \prime} \mathrm{E}$ \\
Sh6 & $37^{\circ} 47^{\prime} 57.90^{\prime \prime} \mathrm{N}$ & $45^{\circ} 23^{\prime} 8.80^{\prime \prime E}$ \\
Sh7 & $37^{\circ} 47^{\prime} 52.00^{\prime \prime} \mathrm{N}$ & $45^{\circ} 22^{\prime} 57.80^{\prime \prime} \mathrm{E}$ \\
Sh8 & $37^{\circ} 48^{\prime} 56.10^{\prime \prime} \mathrm{N}$ & $45^{\circ} 24^{\prime} 25.30^{\prime \prime} \mathrm{E}$ \\
Sh9 & $37^{\circ} 48^{\prime} 56.50^{\prime \prime} \mathrm{N}$ & $4^{\circ} 24^{\prime} 23.80^{\prime \prime} \mathrm{E}$ \\
Sh10 & $37^{\circ} 48^{\prime} 55.30^{\prime \prime} \mathrm{N}$ & $45^{\circ} 24^{\prime} 19.80^{\prime \prime} \mathrm{E}$ \\
Sh11 & $37^{\circ} 48^{\prime} 50.80^{\prime \prime} \mathrm{N}$ & $45^{\circ} 24^{\prime} 26.90^{\prime \prime} \mathrm{E}$ \\
Sh12 & $37^{\circ} 48^{\prime} 55.80^{\prime \prime} \mathrm{N}$ & $4^{\circ} 24^{\prime} 28.00^{\prime \prime} \mathrm{E}$ \\
Sh13 & $37^{\circ} 48^{\prime} 57.60^{\prime \prime} \mathrm{N}$ & $45^{\circ} 24^{\prime} 25.20^{\prime \prime} \mathrm{E}$ \\
Sh14 & $37^{\circ} 48^{\prime} 58.40^{\prime \prime} \mathrm{N}$ & $4^{\circ} 24^{\prime} 19.20^{\prime \prime} \mathrm{E}$ \\
Sh15 & $37^{\circ} 49^{\prime} 00.10^{\prime \prime} \mathrm{N}$ & $45^{\circ} 24^{\prime} 13.80^{\prime \prime} \mathrm{E}$ \\
Sh16 & $37^{\circ} 49^{\prime} 00.50^{\prime \prime} \mathrm{N}$ & $45^{\circ} 24^{\prime} 11.10^{\prime \prime} \mathrm{E}$ \\
\hline
\end{tabular}



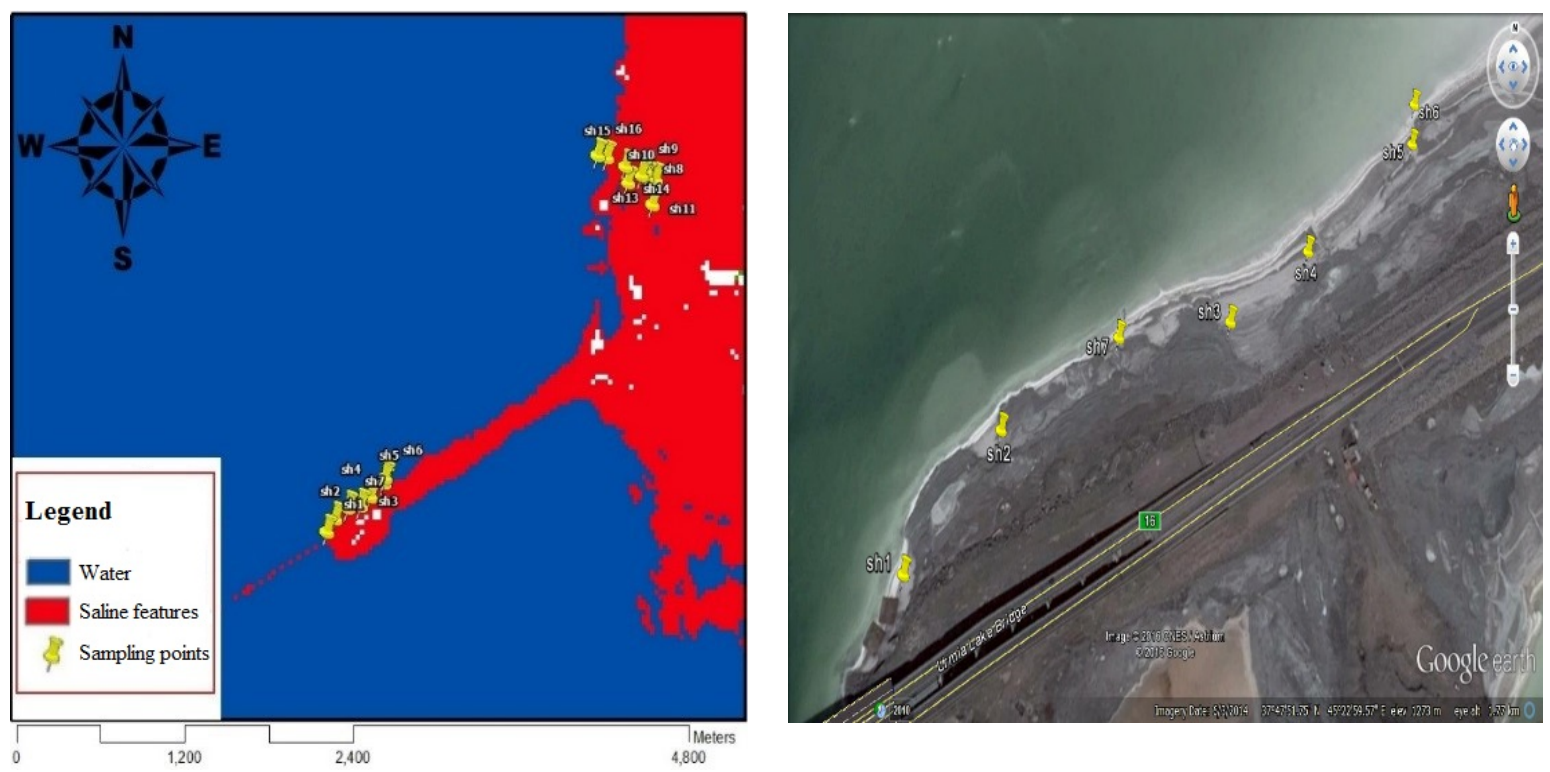

Fig. 2 Locating and marking the sampled points to classify the salinity

Landsat 8 satellite imagery was used to study saline features changes as the process worked in the SSC estimation. Radiometric correction of satellite imagery was carried out, and the lake boundary was determined from the 1999 image. Moreover, areas of the border were removed, and the islands within the lake were masked using the Lake Urmia watershed boundary. ArcGIS Desktop 10.3 and its tool for masking, "Extract by Mask", is used to determine the lake boundary and to mask images. Brightness Index (BI) and Salinity Index (SI) were applied to images to quantify the saline features in the lake. BI uses the near-infrared and red bands, but SI also utilizes the wavelength of green (Equations 6 and 7) (Allbed et al. 2014).

$$
B I=\sqrt{R^{2}+N I R^{2}}
$$

$$
S I=\frac{(N I R \times R)}{G}
$$

A supervised SVM classifier classified the results of the indices into three classes of water, saline features, and non-lake class. Then, the water area of the lake was determined from the results of this classification, and the area was removed from the total salinity index results. Therefore, only the extracted saline features remained. MATLAB coding was performed to calculate area and total saline features from masked index results.

\subsubsection{Analyzing changes in water surface temperature}

SST is one of the most measured variables in environmental studies, and as such, it has received much scientific attention. This parameter and land surface temperature (LST) are two key parameters for many climatic and agricultural studies (Kucera 2009; Pu et al. 2006). Knowledge of past SST variability is essential, as it helps understand how water bodies behave under a changing climate. Temperature affects a range of thermodynamic and biological processes that leave their signatures in the geological record (Minnett 2001; Tomlinson et al. 2011). In this study, MODIS datasets are used for analyzing the SST and LST. MODIS satellite product MOD11A2 was used to investigate the LST. For this purpose, the mean SST differences were studied both in July (warm weather) and January (cold weather).

The changes in water temperature were tracked independently for the northern and southern parts to examine the environmental impacts of the causeway to investigate the effects of the construction of the causeway. These effects can be considered as a trace of the affected flow regimes. For this purpose, the MODIS product long-wave infrared (LWIR) SST, which uses the 11 and $12 \mu \mathrm{m}$ spectral bands, is utilized. This product returns the skin SST in units of ${ }^{\circ} \mathrm{C}$. The product algorithms, methodology and accuracy, is described in (Kilpatrick et.al. 2015). According to Kilpatrick et.al. 2015 MOD11A2 product median residual is $-0.145 \mathrm{~K}$, Standard Deviation (SD) is $0.510 \mathrm{~K}$, and robust deviation is $0.380 \mathrm{~K}$. 
2.2. Emotional artificial neural network (EANN)

EANN is a new generation of ANN-based models that include an artificial emotional system that can give off hormones to regulate the operation of neurons and the hormonal weights (Lotfi E. and Akbarzadeh M.R. 2014). It can be adjusted by the input and output values of the neurons. Contrary to conventional ANN, the information can be reversibly transformed between input and output elements in each neuron of EANN, as illustrated in Fig.1. These neurons also produce dynamical hormones of $\mathrm{Ha}, \mathrm{Hb}$ and $\mathrm{Hc}$, which are primarily initialized based on the pattern of input and output values and later are modulated through the training process. The hormonal coefficients can influence other neuron components such as net function, activation function, and weights. The dotted and solid lines in Fig. 3 represent the hormonal and neural routes of information, respectively. The ith output of the proposed EANN with three hormones of $\mathrm{Ha}, \mathrm{Hb}$ and $\mathrm{Hc}$ can be calculated as follows (Nourani, 2017):

$$
Y_{i}=\underbrace{\left(\lambda_{i}+\sum_{h} \sigma_{i, h} H_{h}\right)} \times f(\sum_{j}[\underbrace{\left(\beta_{i}+\sum_{h} \zeta_{i, h} H_{h}\right)} \times \underbrace{\left(\theta_{i, j}+\Phi_{i, j, k} H_{h}\right)} X_{i, j})+\underbrace{\left(\alpha_{i}+\sum_{h} \chi_{i, h} H_{h}\right)}]
$$

(1)

(2)

(3)

(4)

where the overall artificial hormones are given as:

$$
H_{h}=\sum_{i} H_{i, h} \quad(h=a, b, c)
$$

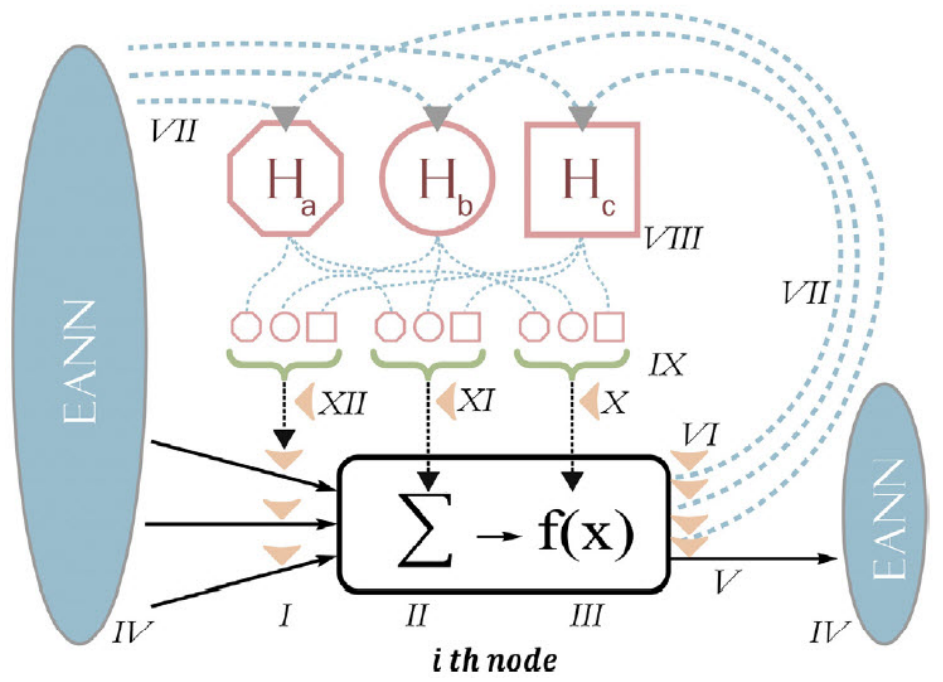

Fig.3 A node of EANN and emotional unit (Nourani, 2017)

In Eq. 8, term (1) indicates the applied weight to the activation function (f). It comprises the constant neural weight of $\lambda_{i}$ and dynamic hormonal weight of $\sum_{h} \sigma_{i, h} H_{h}$. The weight imposed to the net function is indicated by term (2), the term (3) represents applied weight to the $X_{i, j}$ emanating from the jth node of the former layer and eventually, the term (4) shows the bias of the net function, involving both constant neural and hormonal weights of $\mu_{\mathrm{i}}$ and $\sum_{h} \chi_{i, h} H_{h}$.

The contribution of overall hormonal level (i.e., $H_{h}$ ) among the hormones is controlled by $\sigma_{i, h}, \Phi_{i, j, k}, \zeta_{i, h}$, and $\chi_{i, h}$, factors which, in turn, $i$ th node output (Yi) will give hormonal feedback of $H_{i, h}$ to the network as (Nourani, 2017):

$$
H_{i, h}=\text { glandity }_{i, h} \times Y i
$$

Where the glandity factor should be calibrated in the training phase of the EANN model to prepare an acceptable level of the hormone to the glands. Several procedures may be exerted to initialize the hormonal values of the hormonal values of $H_{h}$ according to the input samples. Subsequently, considering the network output $\left(Y_{i}\right)$ and Eqs. 
9 and 10, the hormonal values are renovated through the learning process to achieve an appropriate adaptation between computed and observed time series.

\subsubsection{Efficiency criteria}

For this study, the values of the efficiency criteria were measured to evaluate the sensitivity of the EANN models to the related inputs, using the determination coefficient (DC) and the root mean square error (RMSE), which were suggested to adequately evaluate prediction models by Legates and McCabe (1999):

$$
D C=1-\frac{\sum_{i=1}^{N}\left(O_{i}-\hat{C}_{i}\right)^{2}}{\sum_{i=1}^{N}\left(O_{i}-\bar{O}_{l}\right)^{2}}, \quad-\infty<\mathrm{DC} \leq 1
$$

$$
R M S E=\sqrt{\frac{\sum_{i=1}^{N}\left(O_{i}-\hat{C}_{i}\right)^{2}}{N}}, \quad 0 \leq \mathrm{RMSE}<+\infty
$$

where $\mathrm{N}, O_{i}, \bar{O}_{l}$ and $\hat{C}_{i}$ are the number of observations, observed data, mean of observed data and computed values, respectively. $\mathrm{DC}$ values close to +1 demonstrate higher performance, and the performance declines as the values move away from +1 , while RMSE values close to 0 represent higher performance.

\section{Results and discussion}

The results of the spatio-temporal analysis are discussed in section 3.1. Also, the EANN modelling and singleinput, single-output neural network-based sensitivity analysis is employed to determine the relative importance and the relationship that the input parameters have with the declining in water level and simultaneous increases in the water temperatures lake's, as the considered health indicators. For this purpose, the utilized input and output data were prepared for some time from 2015 to 2018. The chosen period was selected based on the recent significant period of the lake crisis duration.

In the single-input, single-output neural network-based sensitivity analysis, each collection of the input parameters is imposed independently into an EANN model to predict the health indices. By doing that, the actual relationship between the parameters and the indicator can be determined without considering the influence of the other potential input variables. The values of the efficiency criteria are evaluated to rank the relative importance of the input parameters. In this regard, the observed results are discussed in section 3.2.

\subsection{Spatio-temporal analysis}

3.1.1. Estimation and evaluation of changes in vegetation cover and the water area

The changes in the cultivation of agricultural areas are illustrated in Fig. 4 for 2008 and 2015, and detailed cultivation of the agricultural regions using PTF classification between 2005 to 2015 can be seen in Fig. 6 . According to the result of (Sulla-Menashe et al. 2019) that performed for accessing the accuracy of the MCD12Q1, this product has an overall accuracy of $73.6 \%$. More details regarding this product accuracy are available in (SullaMenashe et al. 2019). For better visualization of the data, the classes with an area less than 200 square kilometres have been removed from Fig. 4, as shown in Fig. 5. The results show an increase in the shrub, cereal cropland, and broadleaf croplands cover areas from $7959 \mathrm{~km}^{2}$ in 2008 to $8692 \mathrm{~km}^{2}$ in 2015 . The shrub, cereal cropland, and broadleaf croplands are the most common agricultural production throughout the Lake Urmia watershed (Schulz 2020). 

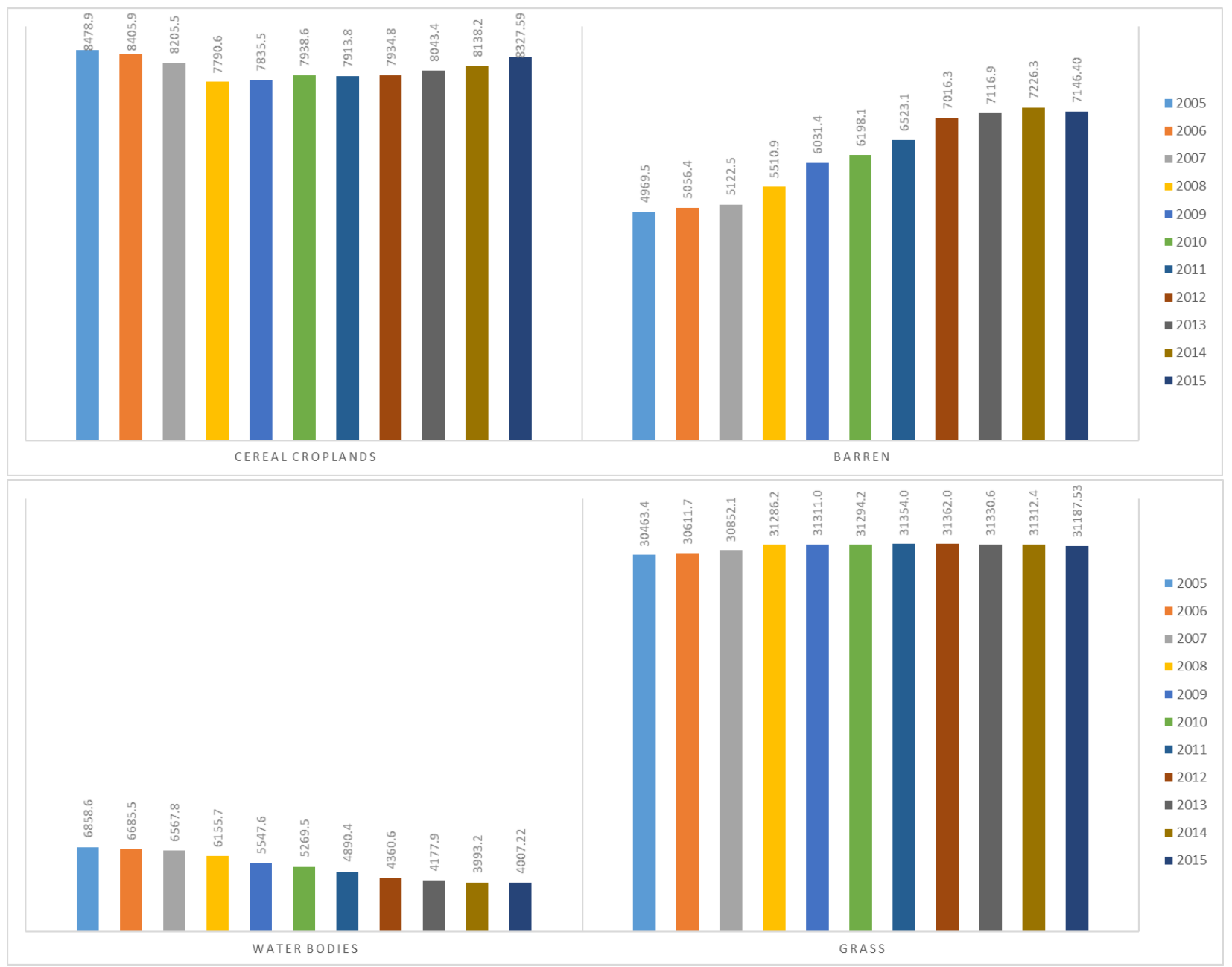

Fig. 4 changes in the agricultural areas between 2005 to 2015
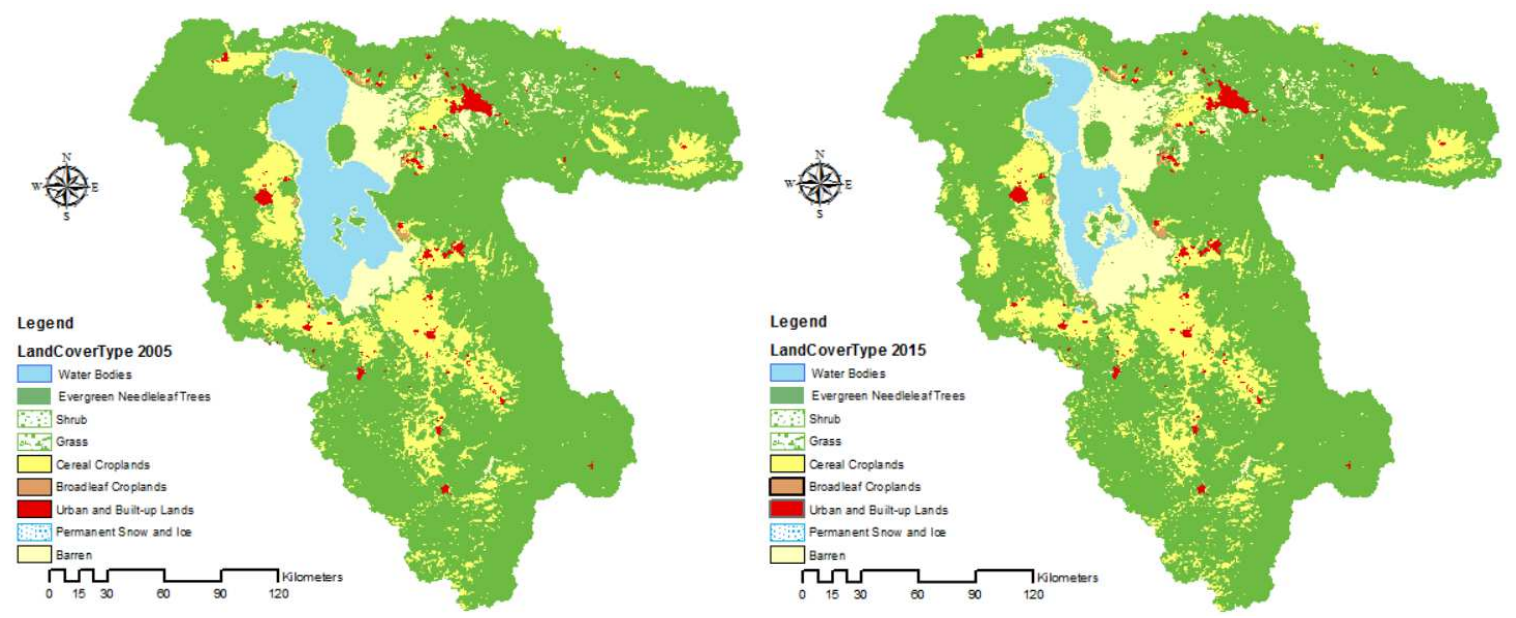

Fig. 5 PTF classification of Lake Urmia for 2005 to 2015

The results demonstrate an alarming increase in cultivated agricultural areas in the related watershed,

simultaneous with the decrease in the lake area.

\subsubsection{Estimation of precipitation and evapotranspiration}

The long term precipitation data records by Iran Water Resource Management Company shows several fluctuation patterns during the 40 years (1975-2015). The PERSIANN precipitation data illustrates from 2005 to 2015, except for 2006 and 2007, always mean annual precipitation is lower than the long-run (40 years) mean yearly 
precipitation averaged in Lake Urmia. However, the mean annual precipitation was $131(\mathrm{~mm})$ the long-run mean

annual precipitation averaged was 340 (mm) in 2011 (IWPMC 2015); this significate decrease may change the water resources in the watershed of Lake Urmia (Fig. 6). The CHRS data portal report shows that this study's precipitation data has MAE, correlation, mean monthly RMSE and mean monthly normalized RMSE of 15.45 $(\mathrm{mm}), 0.678,16.509(\mathrm{~mm})$ and 0.573 in comparison to the National Oceanic and Atmospheric Administration Hdro-Estimator (NOAA-HE) dataset.

ET plays a critical role in balancing the water cycle in an endorheic watershed like the Lake Urmia watershed. The results show a meaningful increase in mean annual ET throughout the watershed ET rose from 205.6029 $\mathrm{kg} / \mathrm{m}^{2} /$ year in 2008 to $283 \mathrm{~kg} / \mathrm{m}^{2} /$ year in 2015 (Fig. 7); this significate change may be due to climate change (Liou 2014). Fig. 7 represents the changes in ET throughout the Lake Urmia watershed in 2005 and 2015. The most share of mean ET belongs to the areas assigned for agriculture, such as shrub, cereal cropland, and broadleaf croplands (see Fig. 5 and Fig. 7). For a better comparison between changes in the mean annual precipitation and ET changes, Fig. 6 combined both data shows in $\mathrm{kg} / \mathrm{m}^{2} /$ year (water density considered approximately $1000 \mathrm{~kg} / \mathrm{m}^{3}$ ) (Stanislawski 2015). As Fig. 6 shows, in 2005, 2008, 2009, 2010, 2011, 2012, 2013, and 2015 the mean annual ET is more than the mean annual precipitation. It can result that during these years, the water input (precipitation) to the Lake Urmia watershed was less than the output water (ET). For a more detailed analysis, the mean annual ET without considering the effect of agriculture is represented in Fig 6. For this purpose, the ET values of the agricultural areas were replaced with mean ET values of these areas if they were not agricultural. For example, in 2009 , the ET values of agriculture are estimated with the mean annual $287 \mathrm{~kg} / \mathrm{m}^{2} /$ year, which were replaced with $225 \mathrm{~kg} / \mathrm{m}^{2} /$ year. This value is the mean ET value of the areas that the previous year was not assigned as agriculture in the same place. As shown in Fig. 6, agriculture can play a remarkable role in water balance in the watershed.

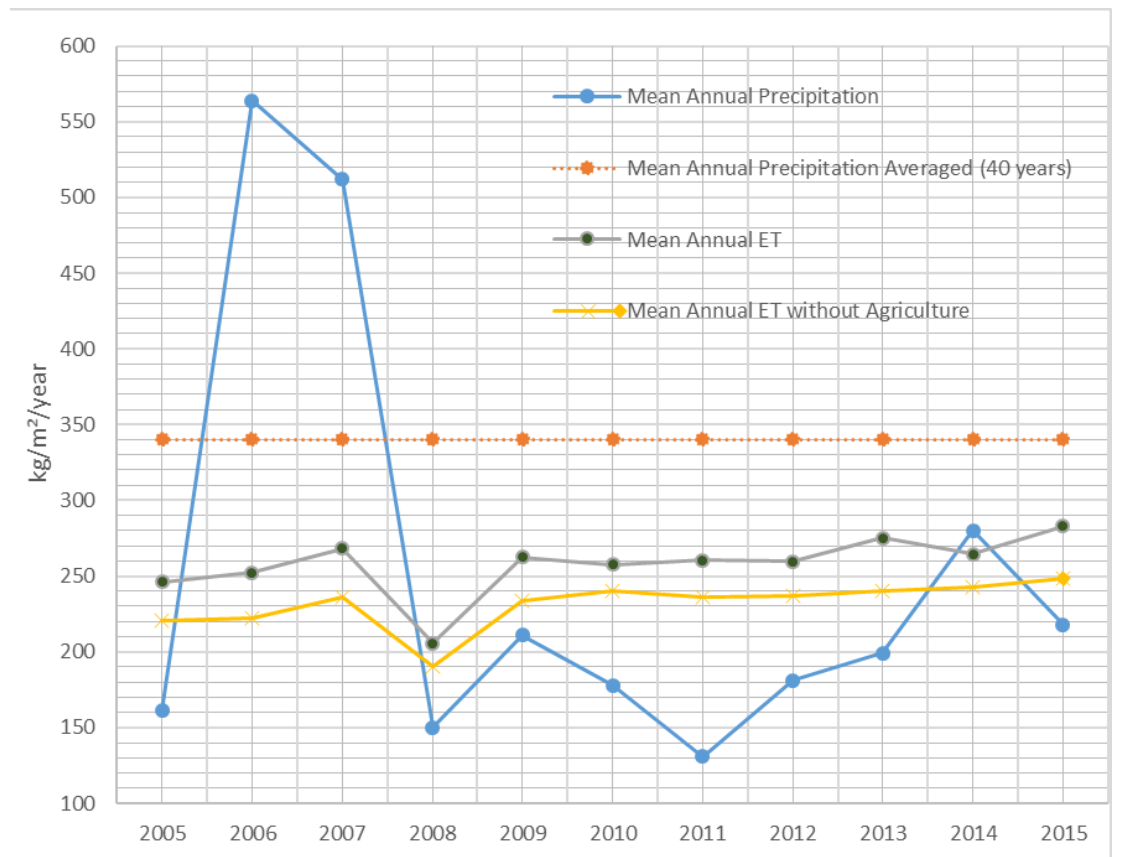

Fig. 6 changes in the mean annual precipitation between 2005 to 2015 in comparison to long-run (40 years) mean yearly precipitation averaged and mean annual ET 


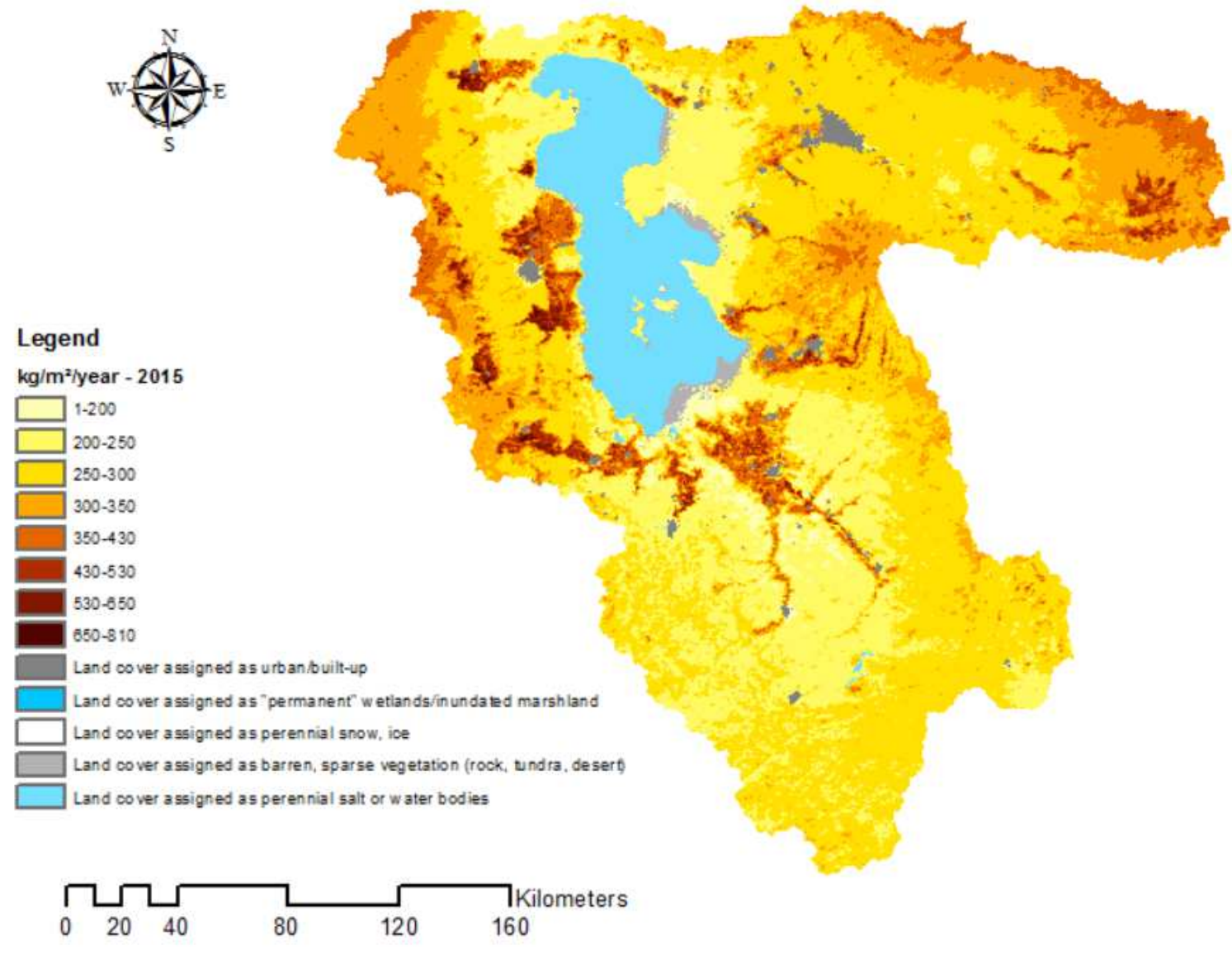




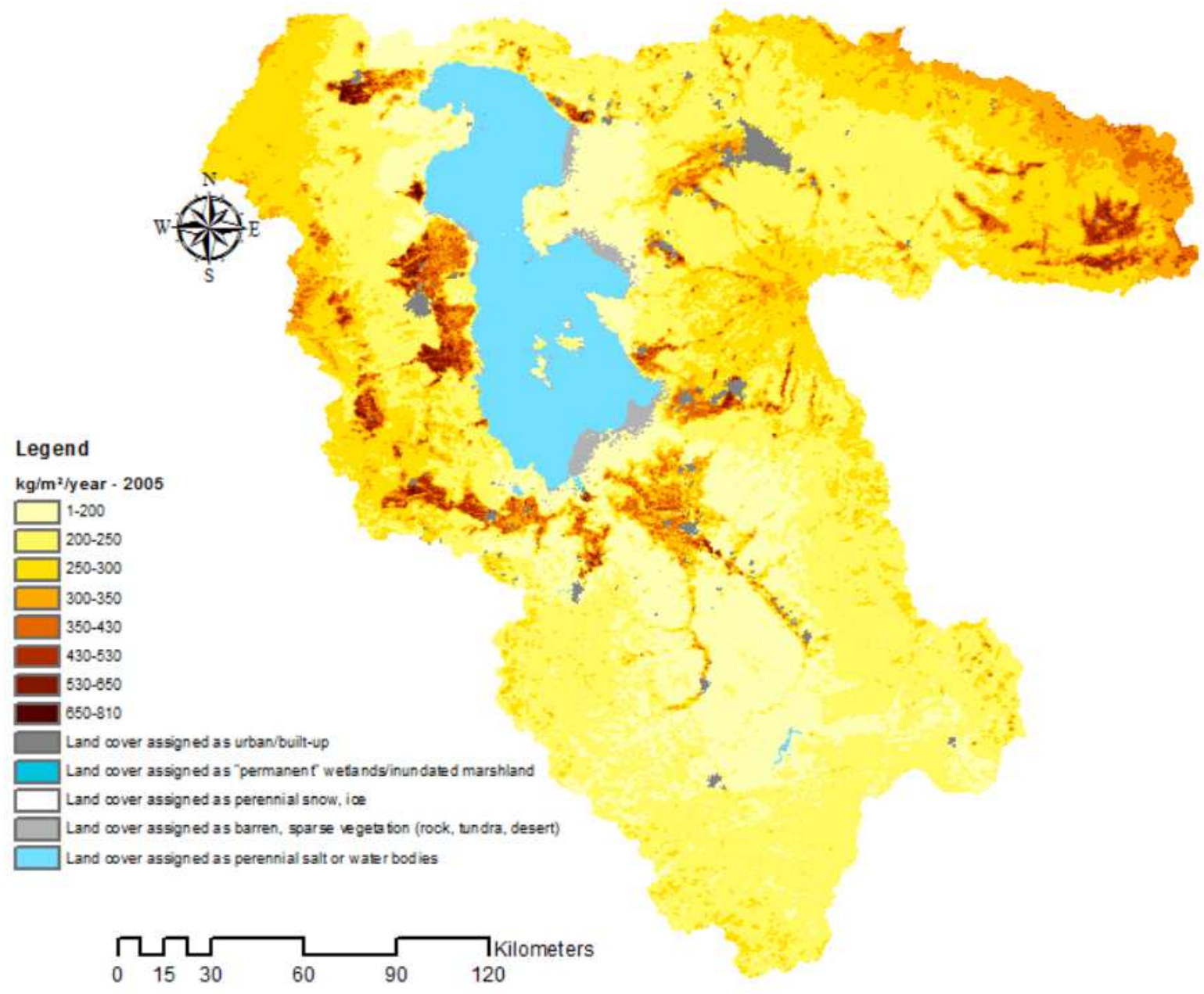

Fig. 7 changes in ET throughout the Lake Urmia watershed in 2005 and 2015

3.1.3. Evaluation of the impacts of the causeway (differences between the northern and southern parts of the lake) Estimation of suspended sediment concentration

413 In this study, three typical indices were used to determine sediment content. The average results of each index were calculated to investigate SSC changes over the considered period (2000-2015), and the results are presented in Fig. 8. The lower the NSMI and BR values, the cleaner the water, and the larger these values indicate the increase in SSC in the study area. The values of these indices have increased per year, indicating the increment in sedimentation rate, as shown in Fig. 8. Also, both BR and NSMI indices have provided better results compared to NDSSI. This result agrees with the results obtained by (Allbed 2014; Bouaziz 2011). These studies show BR and NSMI indices have a better performance in arid areas with low vegetation cover. 


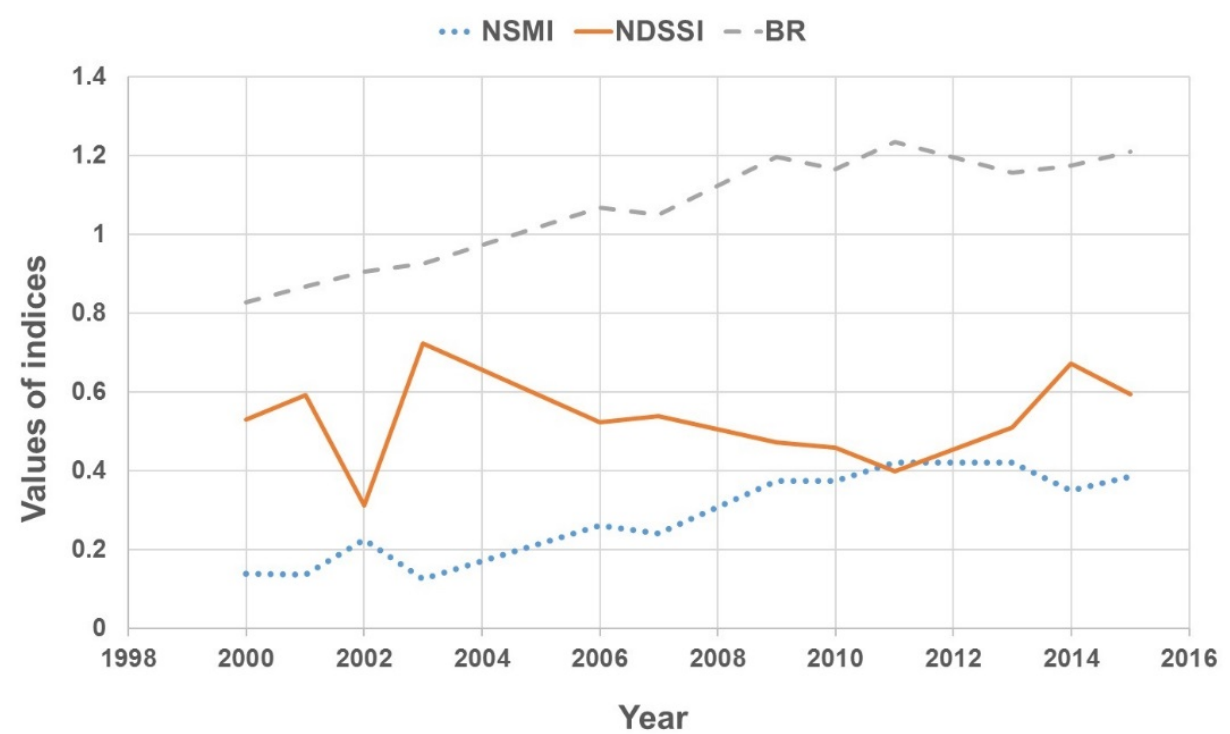

Fig. 8 Average of sediment indices results for the years 2000 to 2015

For further investigation, the mean SSC was calculated for the north and south parts of the lake, separately. The causeway is considered the boundary that divided the lake into two separate north and south parts. For this purpose, the north and south boundaries of the lake were determined. Then, the north and south parts of the lake were cropped from the imagery, and the mean SSC was calculated. The corresponding results are given in Fig. 9.

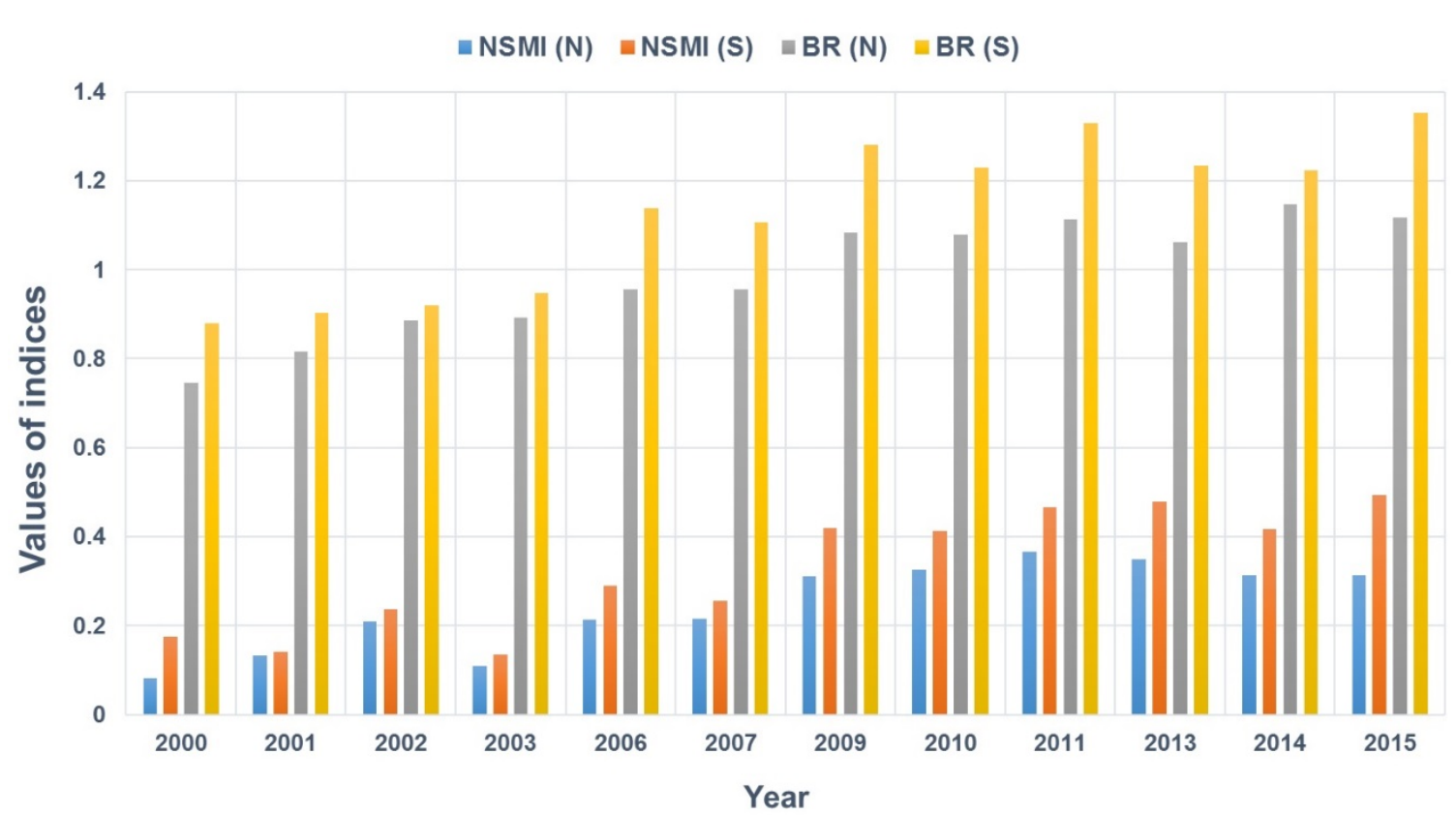

Fig. 9 Average of sediment indices results for the north and south parts of Lake Urmia (2000-2015)

The results indicate that SSC in the south part of the lake is more than the north part, and SSC has increased in

the study area from 2000 to 2015. The SSC maps for the starting and ending years (2000 and 2015) are presented in Fig. 10 to illustrate the results better. 
(a)

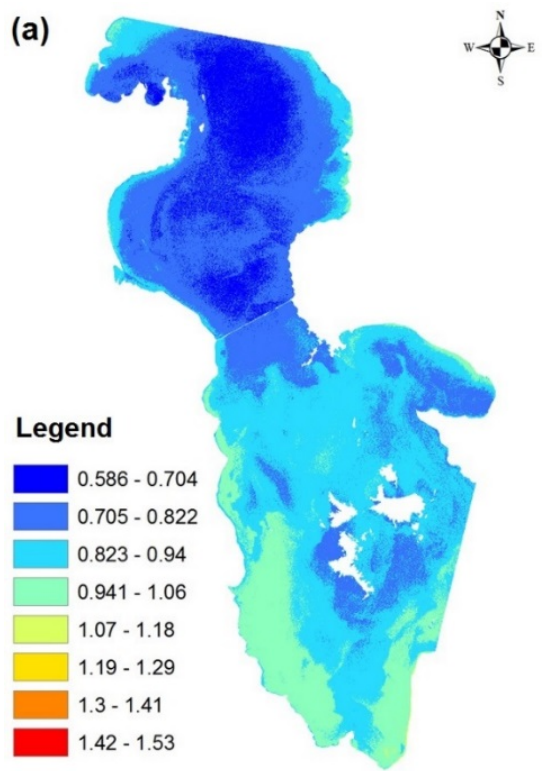

(b)

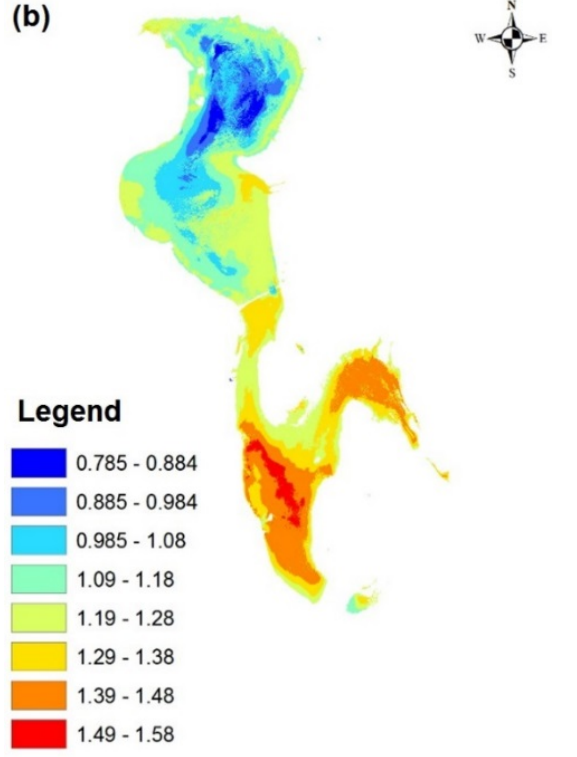

Fig. 10 The SSC maps obtained from BR index for the years, a) 2000 and b) 2015

\section{Evaluation of saline features}

Lake Urmia is the world's second-largest permanent hypersaline lake (Alesheikh et al. 2007). Due to the high salinity of the lake water, salt deposits are formed after any drought occurrence (Stone 2015), and saline soils and salt crusts are recognizable textures and properties in remotely sensed imagery (Chaturvedi et al. 1983; Singh and Srivastav 1990; Srestha and Farshad 2009). The development of the salinization area is visualized in Fig. 11 for the years 1999 and 2016. The observed changes in the area were compared with consideration of the lake shape 1995 (when the lake reached its maximum expansion during the studied period) as the base area.

The trend of changes in the saline features around the causeway is visualized in Fig. 12. The incremental trend of saline expansion can be observed, especially along the northern edge of the causeway. Also, as shown in Fig 12 , the saline area borders in 2016 exceed the maximum recorded wet area of the lake in 2000 . This could be caused by salt deposits being transported several kilometres away from the lake by windblown salt-storms.

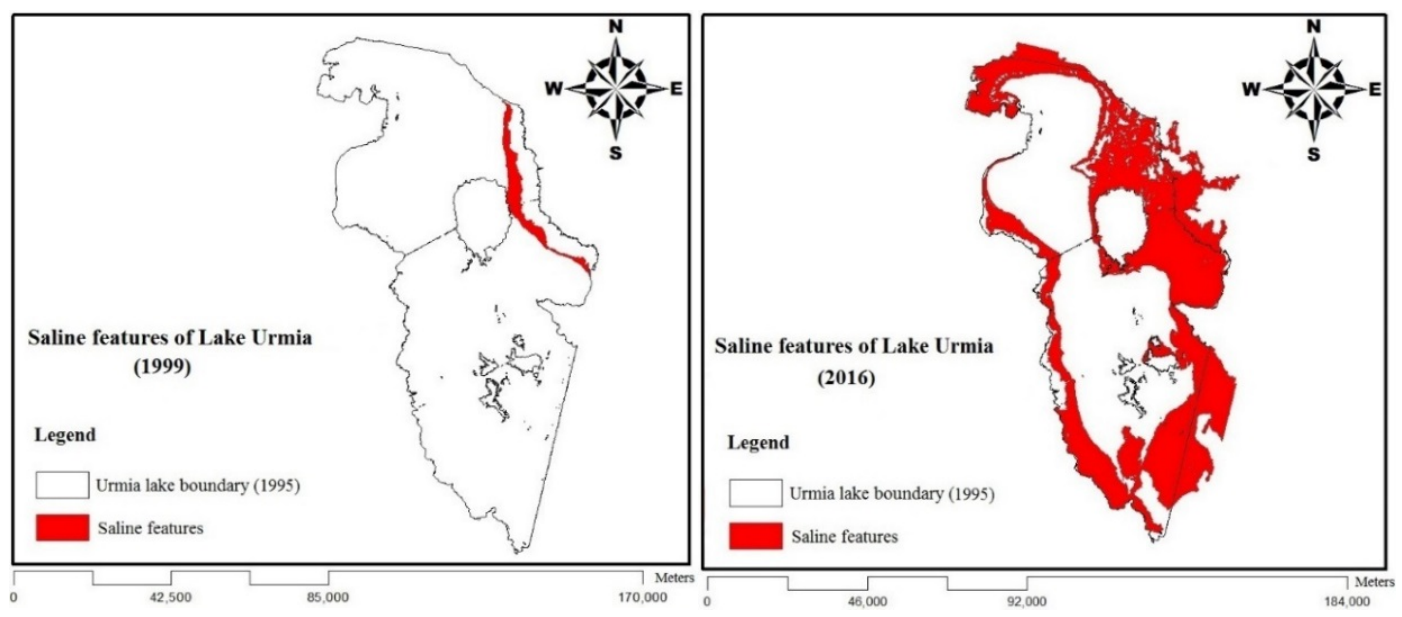

Fig. 11 Maps of the salinization areas for the years 1999 and 2016 

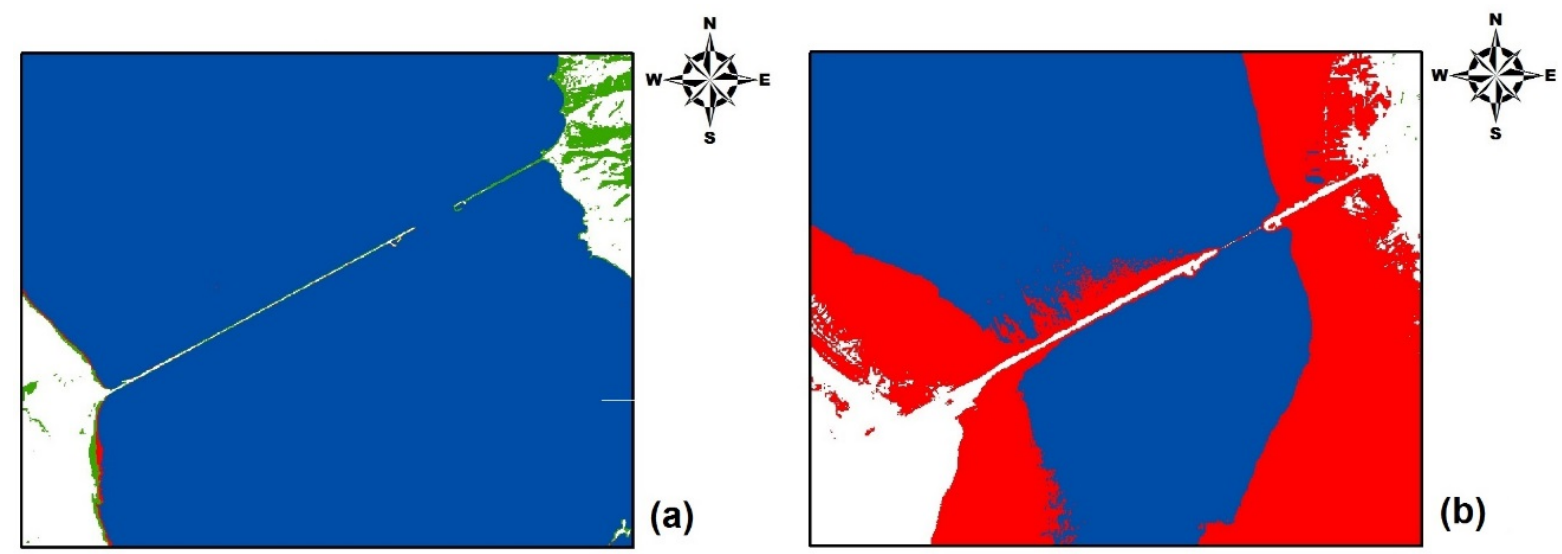

Fig. 12 Changes in saline features around the causeway: a) 2000, b) 2016

Furthermore, the saline features around the lake were quantified using two types of spectral transformation for the period 2000-2015. The drought has developed, and more parts of the lake have been turned into a salt pan. The trend of changes in the saline features around Lake Urmia from 2000 to 2015 is shown in Fig. 14. The results indicate a significant increase in saline features around the lake during the studied period, from $287.718 \mathrm{~km}^{2}$ to $3006.5 \mathrm{~km}^{2}$, consequently decreasing lake water.

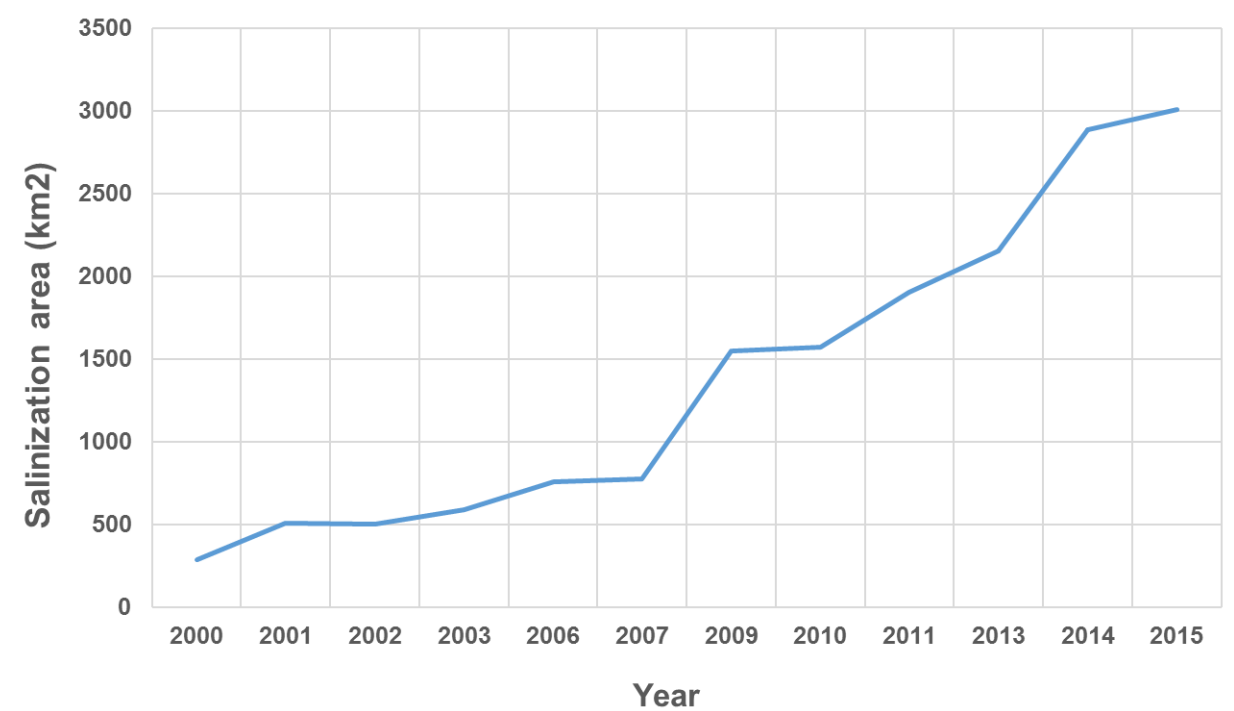

Fig. 13 Trend of changes in the saline features around the lake from 2000 to $2015\left(\mathrm{~km}^{2}\right)$

\section{Changes in SST}

For investigating the effect of the causeway, the changes in SST were tracked separately for the northern and southern halves. For this purpose, the mean SST differences between the northern and southern parts were studied for the warm and cold seasons of the years from 1999 to 2015. This study considers the period between 22 September to 20 March as cold seasons and from 21 March until 21 September as warm seasons. The results can be considered as a trace of the affected flow regimes. For this purpose, the measured values are shown in Fig. 14 for the years 1999 and 2015. The trend of the changes in mean SST is illustrated in Fig. 15. The results show that the SST values in the northern part have been higher than those of the southern one in the warm season, while the SST in the southern part has been higher than the northern part, with an average of $0.2^{\circ} \mathrm{C}$.

The variations in the lake's SST are considered as other significant parameters. SST is one of the most measured variables in environmental studies and is a key parameter for many climatic and agricultural studies (Sekertekin and Bonafoni 2020). Knowledge of related past values is essential, as it helps understand how water bodies behave under a changing climate and the effects on a range of thermodynamic and biological processes. The months of 
August and January were selected for the warm and cold periods of the year, respectively. The trends of the changes in measured mean SST for the warm and cold seasons are displayed in Figs. 16 and 17 respectively for the period from 2001 to 2015 . It is observed that in 2015 , the SST values experienced an increase of $0.65{ }^{\circ} \mathrm{C}(3.45$ ${ }^{\circ} \mathrm{C}$ to $4.13{ }^{\circ} \mathrm{C}$ ) in 2001 . Also, the overall SST was measured from 2001 to 2015 and indicated an increase from $24.5^{\circ} \mathrm{C}$ in 2001 to $29.68^{\circ} \mathrm{C}$ in 2015 .
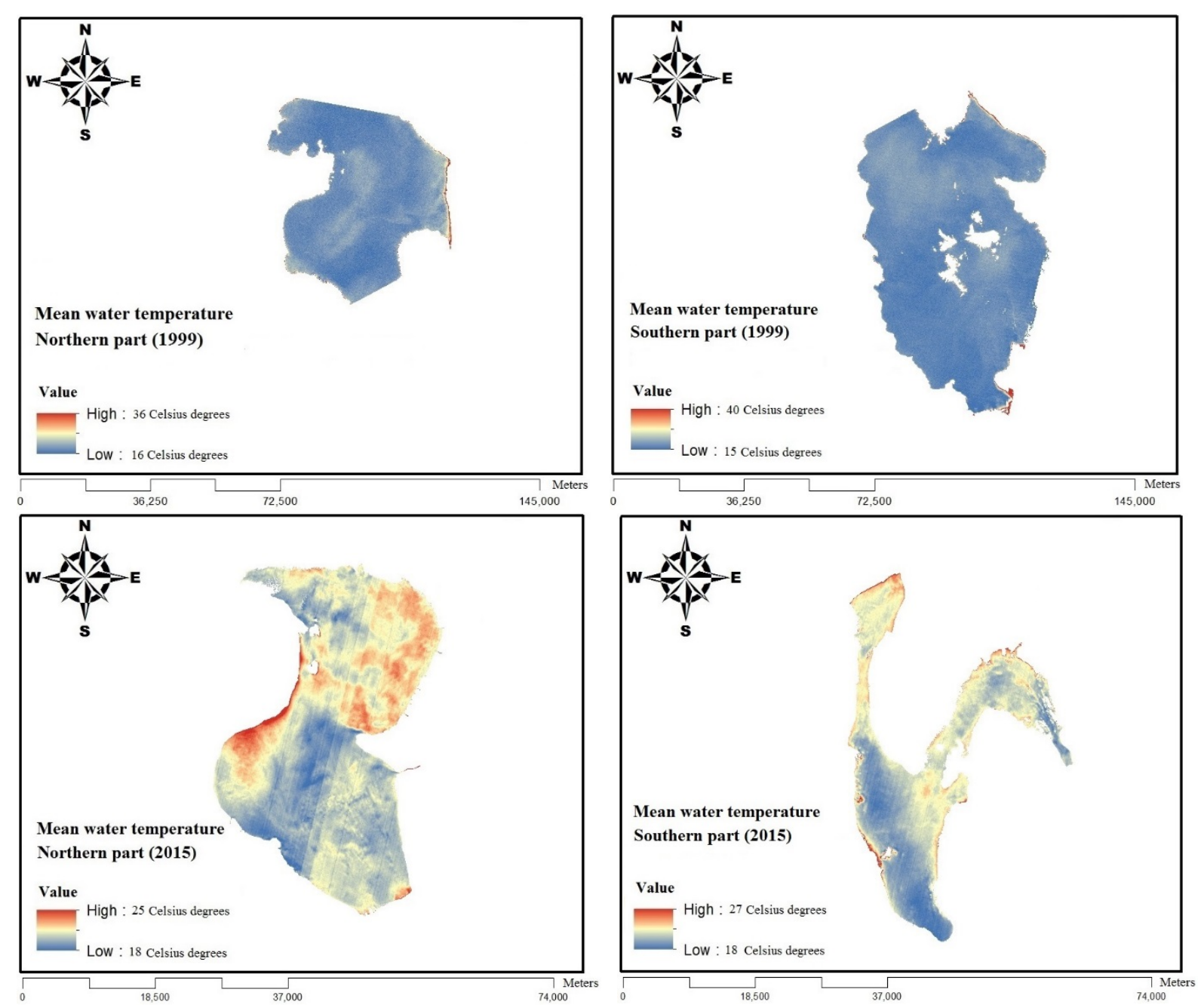

Fig. 14 Changes in SST for the northern and southern halves for the years 1999 and 2015

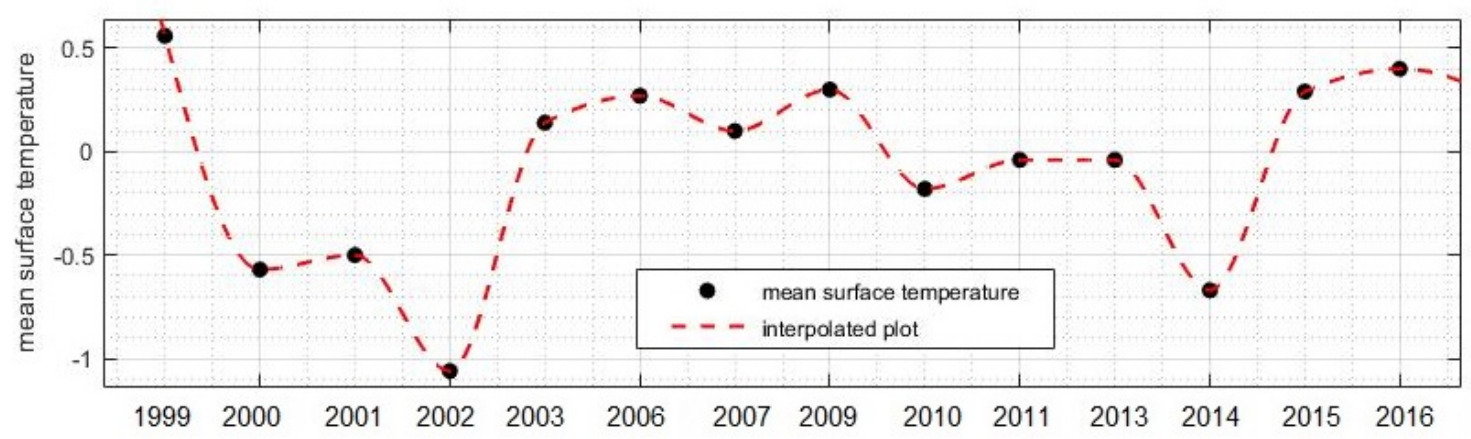

Fig. 15 Trend of changes in mean SST between the northern and southern halves 


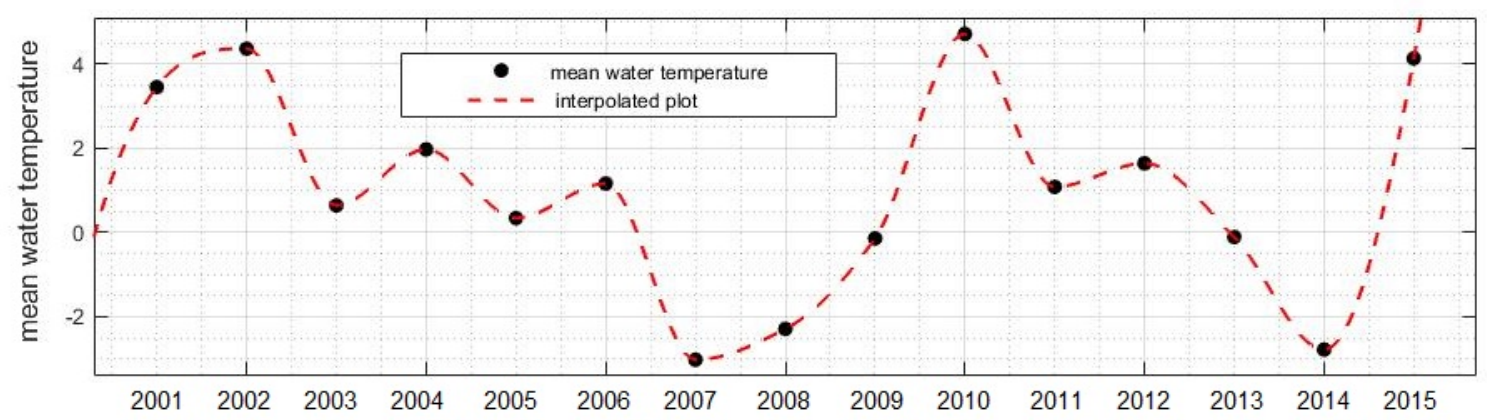

Fig. 16 Trend of changes in measured mean SST for the cold seasons

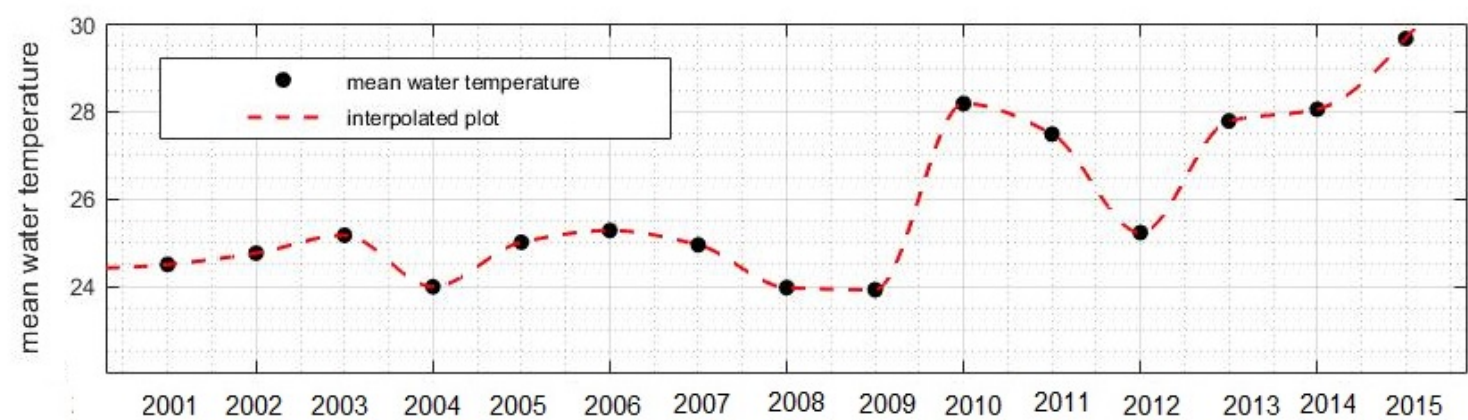

Fig. 17 Trend of changes in measured mean SST for the warm seasons

\subsection{Sensitivity analysis using EANN model}

The procedure of implementing the EANN models is explained in this section. The results of the input-output sensitivity analysis between the considered hydro-ecological factors and the health indicators (water temperature and WL) are discussed to determine their relative correlation. The investigation period is chosen for 2015 to 2018 as the considerable period of the lake crisis duration. The study database, including the precipitation, ET, SST, SSC, saline features, vegetation, runoff, and water level, were preprocessed for 8-day intervals. Datasets of the precipitation, evapotranspiration, sea surface temperatures, suspended sediment concentration, saline features, and vegetation was obtained via the performed spatio-temporal remote sensing analysis, as explained in the previous sections.

Furthermore, the information of hydrometric stations (mainly Nezamabad station $37^{\circ} 02^{\prime} 37^{\prime \prime} \mathrm{N} 45^{\circ} 56^{\prime} 57^{\prime \prime} \mathrm{E}$; Miandoab, Simineh River station $36^{\circ} 57^{\prime} 22^{\prime \prime} \mathrm{N} 46^{\circ} 03^{\prime} 14^{\prime \prime} \mathrm{E}$ and Abajlu Sofla, Nazlu River station $37^{\circ} 43^{\prime} 38^{\prime \prime} \mathrm{N}$ $45^{\circ} 10^{\prime} 00^{\prime \prime} \mathrm{E}$ ) were used to gather the required data for related runoff time series. The required data of water level were obtained via (www.ulrp.ir/en/), all retrieved by LURNC, due to their availability and high accuracy in compression with satellite imagery. These data were also preprocessed for 8-day intervals.

Prior to the model development, all the data are normalized between values of 0 and 1 in order to bring them into the same unit and range. Hence, all the inputs can receive similar attention in modelling the output. A filtering approach was also implemented to denoise within a limited threshold, using MATLAB software.

Contrary to the time series of the temperature, the beginning of the WL time series was shifted backwards for 80 days in WL-output models. This period was selected based on obtaining the best-observed efficiency criteria for the different shift times. The estimated shift time can also be interpreted as a physical concept for the lag between the considered hydro-ecological inputs and their effects on the decrease in the water level.

Considering 6 input parameters and 2 output indicators, 12 scenarios were defined, as presented in Table 3. In this regard, the input parameters were categorized into 2 groups, including increased water diversion for irrigated agriculture and the effects of the causeway on the saline features, the anthropogenic factors, and the group of the climate factors. These scenarios were determined based on different input and output combinations for the EANN models. 
Table 3. The considered scenarios to perform the EANN modelling based on the input-output

\begin{tabular}{ccc}
\hline Scenario & Input Variables & Output \\
\hline S1 & Evapotranspiration, Vegetation cover, Precipitation, SSC, Saline features, Runoff & SST \\
S2 & Evapotranspiration, Precipitation, Runoff, Vegetation cover, Saline features & SST \\
S3 & Evapotranspiration, , Precipitation, Runoff, Vegetation cover, SSC & SST \\
S4 & Evapotranspiration, Precipitation, Runoff, Vegetation cover & SST \\
S5 & Evapotranspiration, , Precipitation, Runoff & SST \\
S6 & Vegetation cover, Saline features, SSC & SST \\
S7 & Evapotranspiration, Vegetation cover, Precipitation, SSC, Saline features, Runoff & WL \\
S8 & Evapotranspiration, Precipitation, Runoff, Vegetation cover, Saline features & WL \\
S9 & Evapotranspiration, , Precipitation, Runoff, Vegetation cover, SSC & WL \\
S10 & Evapotranspiration, Precipitation, Runoff, Vegetation cover & WL \\
S11 & Evapotranspiration, , Precipitation, Runoff & WL \\
S12 & Vegetation cover, Saline features, SSC & WL \\
\hline
\end{tabular}

528

In this study, EANN as a new generation of neural networks is exerted to determine the relative importance as well as the relationship that the input parameters have with the declining in water level and concurrent increases in the water temperatures of Lake Urmia. MATLAB was utilized for programming the required code for training the EANN model. Accordingly, a simplified form of EANN training using the backpropagation algorithm is applied for modelling the correlation between the input parameters and the sensitivity of the considered indicators of the lake health indices. A hypersensitivity analysis by changing the number of hidden neurons (1-16), emotional hormones (1-16), training epochs (10-100) is also carried out for determining the best model structure. The optimum forms of the model for the scenarios are obtained using the trial and error method. The model structure with the highest DC and lowest RMSE values in the testing stage is chosen as the best model.

The EANN model results for the considered scenarios are presented in Table 4. It should be pointed out that only the results of the best models are reported. The results of the models in scenarios 4 and 10 with evapotranspiration, precipitation, runoff and vegetation as input variables led to higher performance than the models in other scenarios. The computed values of the SST versus observed ones and water level time series and scatter plots of the testing phases for both scenarios 4 and 10 (best models) are depicted in Figs. 18, 19 and 20, respectively. The results related to the best efficiency criteria can be attributed quantitatively to show that the combination of ET, precipitation, runoff and vegetation cover as inputs give the most successful models for both SST and WL as the outputs, and consequently can be considered the main potential reasons and the most effective parameters for the crisis.

Table 4. Results of EANN model for the considered scenarios

\begin{tabular}{|c|c|c|c|c|c|c|c|c|}
\hline \multirow[b]{2}{*}{ Scenario } & \multirow{2}{*}{$\begin{array}{l}\text { Time } \\
\text { Scale }\end{array}$} & \multirow{2}{*}{$\begin{array}{c}\text { Hidden } \\
\text { neuron } \\
\text { no. }\end{array}$} & \multirow{2}{*}{$\begin{array}{c}\text { Hormone } \\
\text { no. }\end{array}$} & \multirow{2}{*}{$\begin{array}{l}\text { Epoch } \\
\text { no. }\end{array}$} & \multicolumn{2}{|c|}{$\mathrm{DC}$} & \multicolumn{2}{|c|}{ RMSE (normalized) } \\
\hline & & & & & Train & Test & Train & Test \\
\hline $\mathrm{S} 1$ & 8-day & 8 & 3 & 100 & 0.769 & 0.713 & 0.099 & 0.113 \\
\hline $\mathrm{S} 2$ & 8-day & 5 & 3 & 100 & 0.731 & 0.708 & 0.113 & 0.145 \\
\hline S3 & 8-day & 10 & 5 & 100 & 0.709 & 0.670 & 0.137 & 0.163 \\
\hline S4 & 8-day & 5 & 5 & 100 & 0.897 & 0.868 & 0.089 & 0.096 \\
\hline S5 & 8-day & 6 & 4 & 100 & 0.812 & 0.776 & 0.095 & 0.102 \\
\hline S6 & 8-day & 5 & 5 & 100 & 0.643 & 0.581 & 0.178 & 0.207 \\
\hline S7 & 8-day & 5 & 3 & 100 & 0.758 & 0.722 & 0.107 & 0.126 \\
\hline S8 & 8-day & 12 & 5 & 100 & 0.717 & 0.687 & 0.128 & 0.155 \\
\hline S9 & 8-day & 6 & 8 & 100 & 0.720 & 0.701 & 0.117 & 0.142 \\
\hline $\mathrm{S} 10$ & 8-day & 15 & 5 & 100 & 0.791 & 0.754 & 0.096 & 0.107 \\
\hline S11 & 8-day & 10 & 5 & 100 & 0.765 & 0.733 & 0.110 & 0.129 \\
\hline
\end{tabular}




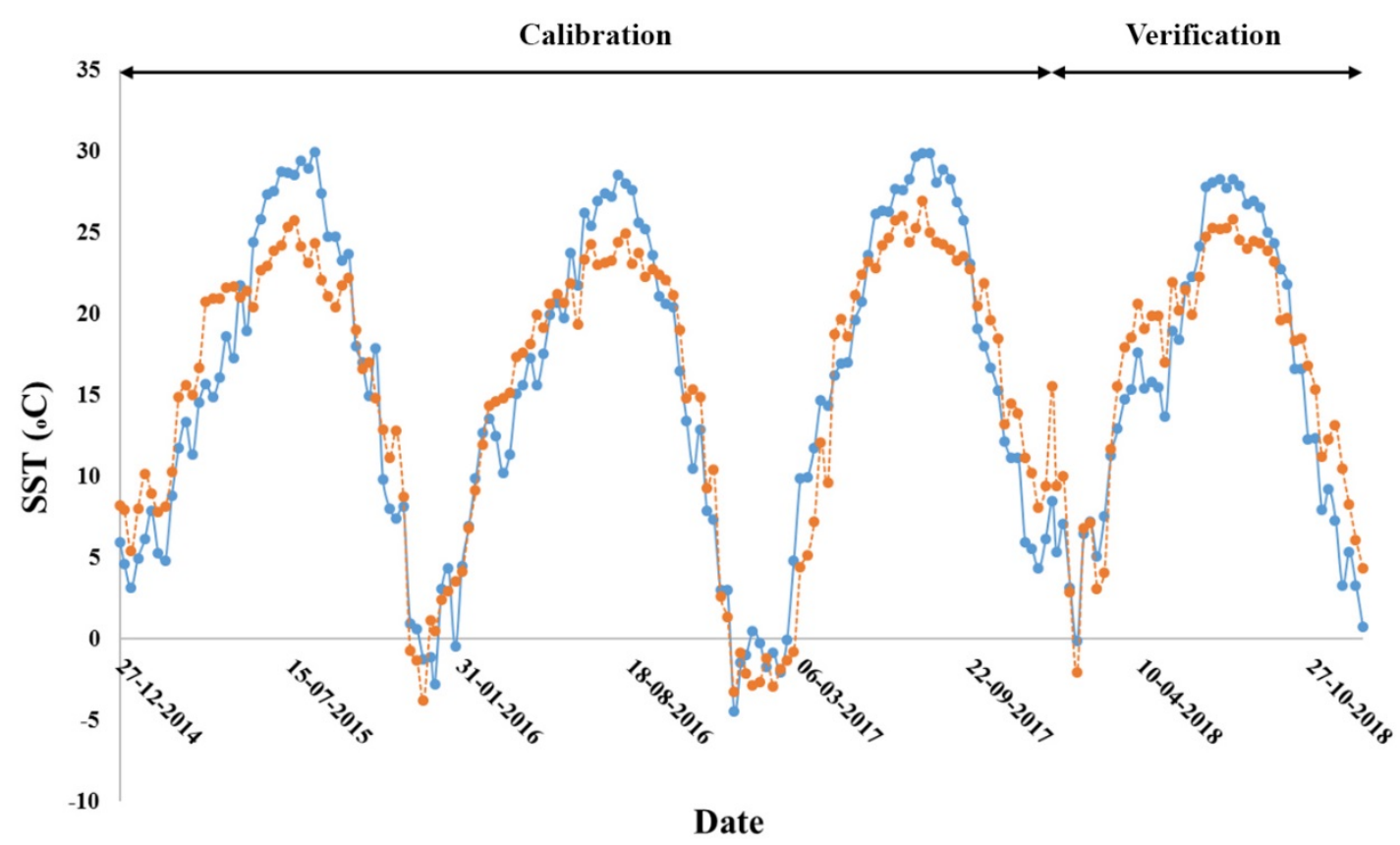

Fig. 18 Observed versus computed SST time series by EANN model via scenario 4

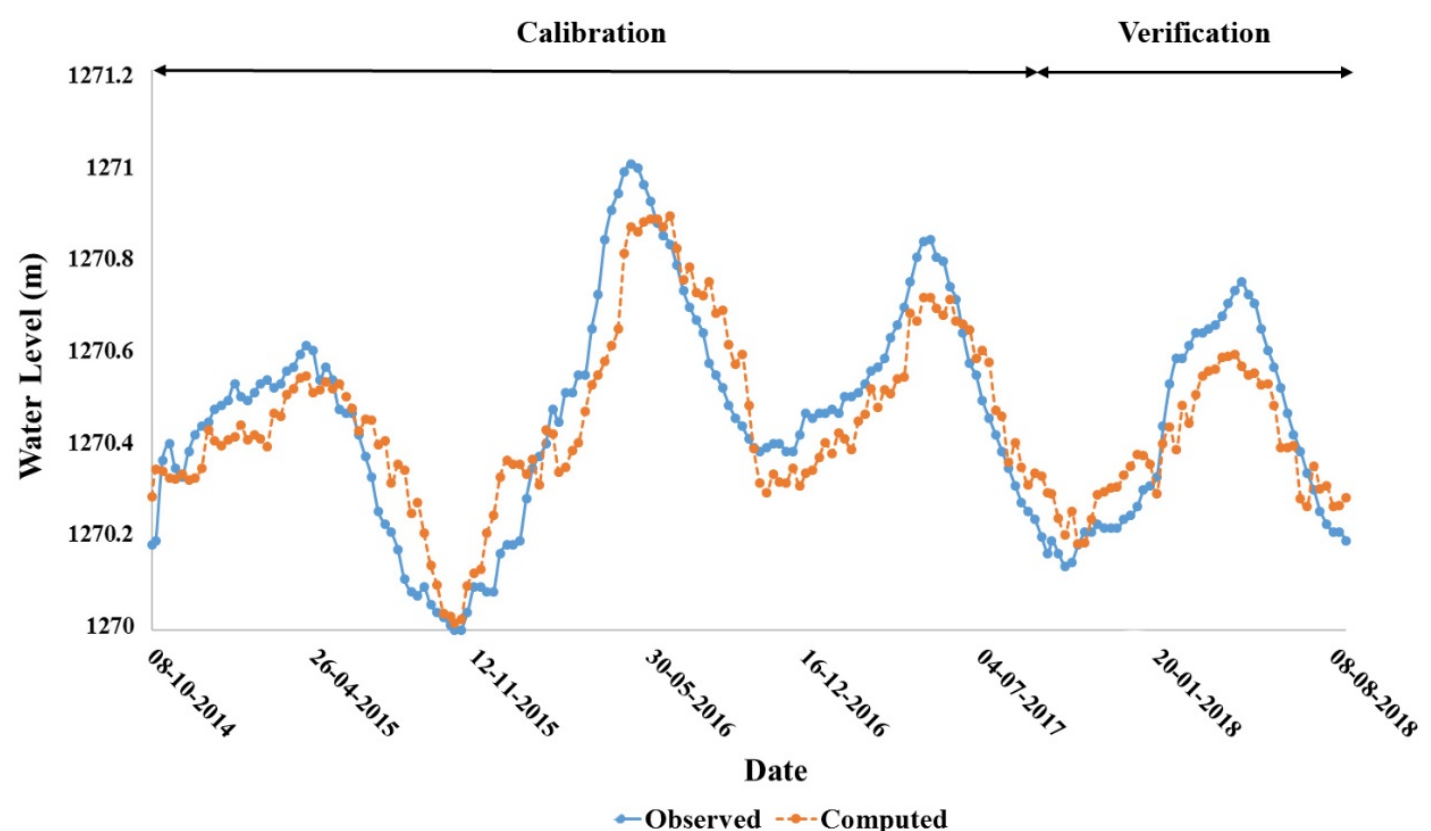




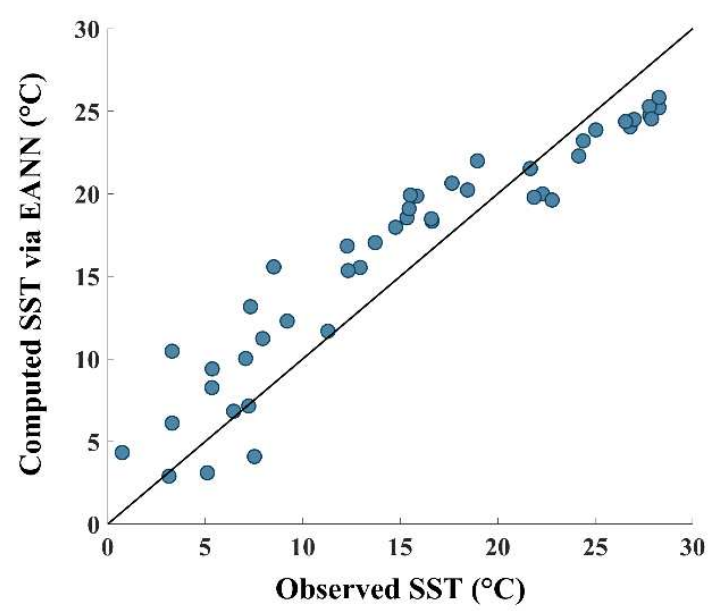

(a)

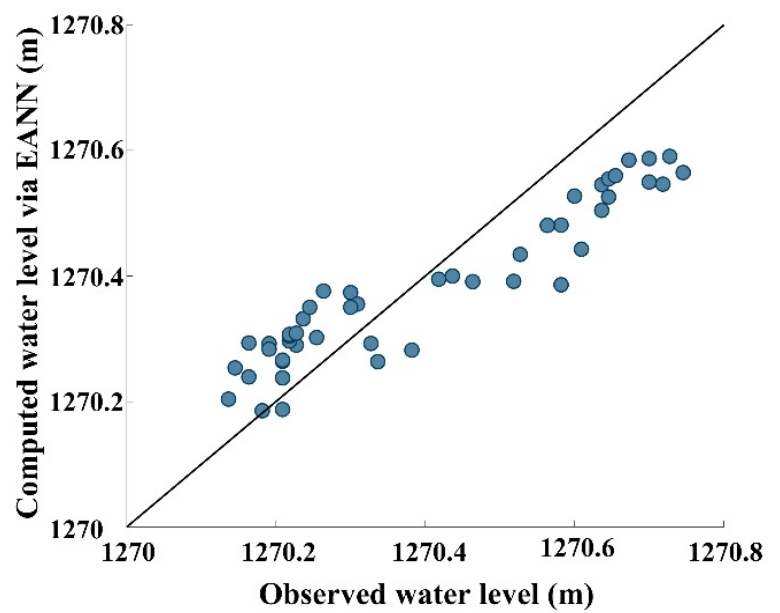

(b)

Fig. 20 Scatter plot of computed versus observed (a) SST and (b) WL time series for scenarios 4 and 10 in the testing stage

\section{Conclusions}

This paper investigates a novel framework for the sensitivity analysis of the interactions between dominant factors (including human-involved and climate factors) and the indices of lake health using an EANN modelling technique. Providing a comprehensive spatio-temporal analysis is another objective of this study in order to detect the onset of deterioration in the parameters. The results are employed to determine the relative importance and the relationship that the input parameters have with the declining WL and simultaneous increases in the SST as the considered health indicators. The following conclusions can be drawn:

The results show that the lake has decreased in size, most noticeably along the southern shorelines. There is a notable increase in saline feature areas around the lake during the studied period. The results demonstrate that the SSC has increased in the lake during recent years. The results also show that the SSC is higher in the south part than the north side. However, the difference in the amount of SSC is more considerable in areas far from the causeway. Therefore, it can only be attributed to the physiology of the southern part, such as the low water depth and water quality of the rivers that feed this part. Analyzing the images and the amount of SSC around the causeway had no significant impact on the SSC pattern.

Also, it is observed that the lake's SST is experiencing a relative increase during recent years. Furthermore, the changes in SST were tracked separately for the northern and southern parts. The results show that the SST values in the northern part have been higher than those of the southern one in the warm season during the studied period, while the SST in the southern part is usually more than the northern part with an average of $0.2^{\circ} \mathrm{C}$. Despite this fact, the results show that the existence of the causeway has had no significant impact on the changes in the SST patterns of the northern and southern halves and that its impact on the uniformity of water in the lake has been minimal. These results are inconsistent with those obtained in previous studies, which have recognized the causeway as the leading cause of the crisis.

The Lake Urmia watershed water balance is defined as water input such as precipitation, output like ET, and reservoirs such as the Lake Urmia and aquifers. From 2005 to 2015, the lake experiences a dramatic decreasing the water level and cover area, which shows changes in the watershed water balance. Therefore, this study aimed to analyze precipitation, ET as the primary input, and output water resources. The results also highlight an alarming decrease in mean annual precipitation and a high increase in mean yearly ET. Climate change can be a reason for these changes. However, the results also show that the overuse of groundwater due to the lowperformance irrigation system (Iran still primarily uses the flooding irrigation system, which originates from deep well waters) leads to a higher mean annual ET. The decrease in water inputs and increases in water outputs for several years resulted in a deficit of water reservoirs in the Lake Urmia watershed. 
The EANN modelling and single-input, single-output neural network-based sensitivity analysis were employed to determine the relative importance and relationship that the input parameters have with water level and simultaneous increases in the SST as the considered health indicators. The utilized input and output data were prepared for some time from 2015 to 2018. The chosen period was selected based on the recent major period of the lake crisis duration. Twelve scenarios were defined based on different input and output combinations for the EANN models. The results of the models in scenarios 4 and 10 with evapotranspiration, precipitation, runoff and vegetation as input variables led to higher performance $(\mathrm{DC}=0.868$ and $\mathrm{RMSE}=0.096$ for $\mathrm{S} 4 ; \mathrm{DC}=0.754$ and RMSE $=0.107$ for $\mathrm{S} 10$ ) than the models in other scenarios.

The relationship between the lake crisis and hydrological drought and anthropogenic factors is always a challenging problem between the residents and NGOs that mostly believe in the mismanagement of human activities as the major cause. However, governmental organizations often believe that climate change is the cause of the crisis. The results of this study can be attributed quantitatively to show that the combination of both climate change and anthropogenic factors, including the overdraft of the agricultural sector, can be considered the main potential reasons for the crisis.

\section{Acknowledgments}

The authors graciously acknowledge Mr. Robert Hart from the University of Ottawa for his review and assistance in improving the language of the paper.

\section{Declarations}

Funding (Not applicable)

Conflicts of interest/Competing interests (Not applicable)

Availability of data and material (Not applicable)

Code availability (Not applicable)

Authors' contributions (Alireza Mojtahedi: conception and design of the work; interpretation of data; Abdolmajid Mohammadian: interpretation of data; Mostafa Azizkhani: acquisition, analysis; Ramin Almasi: acquisition, analysis; Mehran Dadashzadeh: interpretation of data)

\section{References}

Abbaspour M, Javod AH, Mirbagheri SA, Ahmadi Givi F, Moghimi P (2012) Investigation of Lake Drying Attributed to Climate Change. Int J Environ Sci Technol 9 (2): 257-266.

Abdi, J., Moshiri, B., Abdulhai, B., Sedigh, A.K., (2012). Forecasting of short-term traffic flow based on improved neuro-fuzzy models via emotional temporal difference learning algorithm. Eng. Appl. Artif. Intel. 25, $1022-1042$.

Afzali, R., Zaki, Y., Kaviani Rad, M., \& Mohammadkhani, E. (2020). A comparative study of climate change and security challenges of water crisis in cities of Urmia lake and central Iran basins. Journal of Urban Social Geography, 7(1), 167-189.

AghaKouchak A, Norouzi H, Madani K, Mirchi A, Azarderakhsh M, Nazemi A, Nasrollahi N, Farahmand A, Mehran A, Hasanzadeh E (2015) Aral Sea syndrome desiccates Lake Urmia: Call for action. J Great Lakes Res 41(1): 307-311.

Alavi Panah SK, Khodaei K, Jafar Biglo M (2005) Capability of Remotely Sensed Data in the Study of water Quality of the both sides of Urmia Lake Causeway. Res Geogr No.53 (In Persian)

Alesheikh AA, Ghorbanali A, Nouri N (2007) Coastline change detection using remote sensing. Int J Environ. Sci Technol 4: 61-66.

Alizade Govarchin Ghale Y, Altunkaynak A, Unal A (2018) Investigation Anthropogenic Impacts and Climate Factors on Drying up of Urmia Lake using Water Budget and Drought Analysis. Water Resour Manage 32: 325-337. 
Allbed A, Kumar L, Aldakheel YY (2014) Assessing soil salinity using soil salinity and vegetation indices derived from IKONOS high-spatial resolution imageries: Applications in a date palm dominated region Geoderma, 230-231: 1-8.

Almasi R (2016) Investigation of the Urmia Lake crisis based on hydraulic characteristics using satellite data and spatial analysis. Master's thesis, Tabriz University, Iran.

Amirataee, B., \& Zeinalzadeh, K. (2016). Trends analysis of quantitative and qualitative changes in groundwater with considering the autocorrelation coefficients in west of Lake Urmia, Iran. Environmental Earth Sciences, 75(5), 371 .

Ansari, Mohsen, and Mehdi Akhoondzadeh. "Mapping water salinity using Landsat-8 OLI satellite images (Case study: Karun basin located in Iran)." Advances in Space Research 65.5 (2020): 1490-1502.

Arisanty D, Saputra A (2017) Remote Sensing Studies of Suspended Sediment Concentration Variation in Barito Delta. IOP Conference Series: Earth and Environmental Science. 98 (1): 012058.

Azarnivand, A., Hashemi-Madani, F. S., \& Banihabib, M. E. (2015). Extended fuzzy analytic hierarchy process approach in water and environmental management (case study: Lake Urmia Basin, Iran). Environmental Earth Sciences, 73(1), 13-26.

Barzegar, R., Moghaddam, A. A., Soltani, S., Baomid, N., Tziritis, E., Adamowski, J., \& Inam, A. (2019). Natural and anthropogenic origins of selected trace elements in the surface waters of Tabriz area, Iran. Environmental Earth Sciences, 78(8), 254.

Bouaziz, M., Matschullat, J., \& Gloaguen, R. (2011). Improved remote sensing detection of soil salinity from a semi-arid climate in Northeast Brazil. Comptes Rendus Geoscience, 343(11-12), 795-803.

Chen, S. H., Jakeman, A. J. \& Norton, J. P. (2008). Artificial intelligence techniques: an introduction to their use for modelling environmental systems. Mathematics and Computers in Simulation 78 (2-3), 379-400.

Chaturvedi L, Carver KR, Harlan JC, Hancock GD, Small FV, Dalstead KJ (1983) Multispectral remote sensing of saline seeps. IEEE Trans Geosci. Remote Sens 21(3): 239 - 251.

Chaudhari S, Felfelani F, Shin S, Pokhrel Y (2018) Climate and anthropogenic contributions to the desiccation of the second largest saline lake in the twentieth century. J Hydrol 560: 342-353.

Dariane, A., Ghasemi, M., Karami, F., \& Hatami, S. (2019). Urmia Lake desiccation and the signs of local climate changes. Journal of Hydraulic Structures, 5(2), 1-17.

Eimanifar A, Mohebbi F (2007) Urmia Lake (Northwest Iran): a brief review. Saline Syst 3, 5.

Elsharkawy A, Elhabiby M, El-Sheimy N (2012) Quality Control on the Radiometric Calibration of the WorldView-2 Data. Global Geospatial Conference.

Estel, S., Kuemmerle, T., Levers, C., Baumann, M., \& Hostert, P. (2016). Mapping cropland-use intensity across Europe using MODIS NDVI time series. Environmental Research Letters, 11(2), 024015.

Faramarzi N (2012) Agricultural Water Use in Lake Urmia Basin, Iran: An Approach to Adaptive Policies and Transition to Sustainable Irrigation Water Use. Department of Earth Sciences, Uppsala University, 44pp.

Fazel, N., Norouzi, H., Madani, K., \& Kløve, B. (2016). Agricultural crop mapping and classification by Landsat images to evaluate water use in the Lake Urmia basin, North-west Iran. EGUGA, EPSC2016-9250.

Fickas KC, Cohen WB, Yang Z (2016) Landsat-based monitoring of annual wetland change in the Willamette Valley of Oregon, USA from 1972 to 2012. Wetlands Ecol Manage, 24(1): 73-92.

Iran Water Resource Management Company (IWPMC) (2015) Preparation of biometric map of Urmiah lake and fertility sedimentation rate in it between 2013 and 2015 using remote sensing methods and field study. No. 942511

García-Mora, T. J., Mas, J. F., \& Hinkley, E. A. (2012). Land cover mapping applications with MODIS: a literature review. International Journal of Digital Earth, 5(1), 63-87. 
Garousi V, Najafi A, Samadi A, Rasouli K, Khanaliloo B (2013) Environmental Crisis in Lake Urmia, Iran: A Systematic Review of Causes, Negative Consequences and Possible Solutions. Lake Urmia Conservation Institute.

Ghorbanzadeh, O., Feizizadeh, B., \& Blaschke, T. (2018). An interval matrix method used to optimize the decision matrix in AHP technique for land subsidence susceptibility mapping. Environmental Earth Sciences, 77(16), 584.

Goslee SC (2011) Analyzing remote sensing data in R: the landsat package J Stat Softw 43(4): 1-25.

Hesami, A., \& Amini, A. (2016). Changes in irrigated land and agricultural water use in the Lake Urmia basin. Lake and Reservoir Management, 32(3), 288-296.

Hassanzadeh E, Zarghami M, Hassanzadeh Y (2011) Determining the main factors in declining the Urmia Lake level by using System Dynamics Modeling. Water Res. Manage 26 (1): 129-145.Hoseinpour M, Fakheri Fard A, Naghili R, editors (2010) Death of Urmia Lake, a silent disaster investigating causes, results and solutions of Urmia Lake drying. 1st International Applied Geological Congress, Department of Geology, Islamic Azad University, Islamic Azad University-Mashhad Branch, Iran.

Hossain A, Jia Y, Chao X (2010) Development of Remote Sensing Based Index for Estimating/Mapping Suspended Sediment Concentration in River and Lake Environments. In Proceedings of 8th international symposium on ECOHYDRAULICS (ISE 2010) 0435: 578-585

Jaafari SH, Shabani AA, Danehkar A (2013) Investigation of Coastline Change of the Urmia Lake using remote sensing and GIS. Aquat. Biol 1(5): 215-220.

Kabiri K, Pradhan B, Sharifi A, Ghobadi Y, Pirasteh S (2012) Manifestation of Remotely Sensed Data Coupled With Field Measured Meteorological Data for an Assessment of Degradation of Urmia Lake, Iran. Proceedings of the Asia Pacific Conference on Environmental Science and Technology, Kuala Lumpur, Malaysia. February 1-2.

Karbassi A, Bidhendi GN, Pejman A, Bidhendi ME (2010) Environmental impacts of desalination on the ecology of Lake Urmia. J. Great Lakes Res 36(3): 419-424.

Khademi F, Pirkharrati H, Shahkarami S (2015) Investigation of Increasing Trend of Saline Soils around Urmia Lake and its Environmental Impact, Using RS and GIS. J. Geosci 24(94): 93-99 (In Persian).Khatami S (2013) Nonlinear Chaotic and Trend Analyses of Water Level at Urmia Lake, Iran. Master's thesis, Lund University, Sweden.

Khazaei B, Khatami S, Alemohammad SH, Rashidi L, Wu C, Madani K, Kalantari Z, Destouni G, Aghakouchak A (2019) Climatic or regionally induced by humans? Tracing hydro-climatic and land-use changes to better understand the Lake Urmia tragedy. J Hydrol 569: 203-217.

Kilpatrick, K.A., Podestá, G., Walsh, S., Williams, E., Halliwell, V., Szczodrak, M., Brown, O.B., Minnett, P.J. and Evans, R., (2015). A decade of sea surface temperature from MODIS. Remote Sensing of Environment, $165, \mathrm{pp} .27-41$.

Komaki CB (2014) Study of Changes in Lake Urmia Using Satellite Data. The Second National Conference on the Approach of Management of Arid and Desert Areas, Semnan, Iran (In Persian).

Kucera M (2009) Determination of Past Sea Surface Temperatures, in: Steele, J.H. (Ed), Encyclopedia of Ocean Sciences. Academic Press, pp 98-113.

Liou, Y. A., \& Kar, S. K. (2014). Evapotranspiration estimation with remote sensing and various surface energy balance algorithms-A review. Energies, 7(5), 2821-2849.

Lotfi E., Akbarzadeh M.R. (2014). Practical emotional neural networks. J. Neural Networks, 59 (2014) 61-72, http://dx.doi.org/10.1016/j.neunet.2014.06.012.

Maleki, T., Kuhestani, H., ZARIFIAN, S., \& ZARAFSHANI, K. (2019). Factors Affecting Sensitivity to Water Crisis in Eastern Regions of Lake Urmia Basin (Case study: East Azerbaijan Province). 
Mehrian MR, Hernandez RP, Yavari AR, Faryadi S, Salehi E (2016) Investigating the causality of changes in the landscape pattern of Lake Urmia basin, Iran using remote sensing and time series analysis. Environ Monit Assess 188(8): 1-13.

Minnett PJ (2001) Satellite Remote Sensing of Sea Surface Temperatures, in: Steele, J.H. (Ed), Encyclopedia of Ocean Sciences. Academic Press, pp 91-102.

Mitchell DE (2013) Identifying Salinization through Multispectral Band Analysis. Master of Spatial Analysis (MSA). Toronto, Ontario, Canada.

Moghtased-Azar, K., Mirzaei, A., Nankali, H. R., \& Tavakoli, F. (2012). Investigation of correlation of the variations in land subsidence (detected by continuous GPS measurements) and methodological data in the surrounding areas of Lake Urmia. Non-linear Processes in Geophysics, 19(6).

Mohebzadeh, H., \& Fallah, M. (2019). Quantitative analysis of water balance components in Lake Urmia, Iran using remote sensing technology. Remote Sensing Applications: Society and Environment, 13, 389-400.

Montalvo LG (2010) Spectral Analysis of Suspended Material in Coastal Waters: A Comparison between Band Math Equations (Mayaguez: Department of Geology University of Puerto Rico).

Nguyen, P., Shearer, E. J., Tran, H., Ombadi, M., Hayatbini, N., Palacios, T., ... \& Kuligowski, B. (2019). The CHRS Data Portal, an easily accessible public repository for PERSIANN global satellite precipitation data. Scientific data, 6(1), 1-10.

Okhravi S, Eslamian S, Tarkesh Esfahany S, Fb A (2017) Drought in Lake Urmia, in: Eslamian S, Eslamian F (Eds.), Drought and Water Scarcity: Environmental Impacts and Analysis of Drought and Water Scarcity. Boca Raton: CRC Press, 605-617.

Pitman MG, Läuchli A (2002) Global Impact of Salinity and Agricultural Ecosystems, in: Läuchli A, Lüttge U (Eds.), Salinity: Environment - Plants - Molecules. Springer, Dordrecht, pp. 3-20.

Pu R, Gong P, Michishita R, Sasagawa T (2006) Assessment of multi-resolution and multi-sensor data for urban surface temperature retrieval. Remote Sens Environ 104(2): 211-225.

Ritchie JC, Cooper CM, Frank R, Schiebe FR (1990) The relationship of MSS and TM digital data with suspended sedimensts, chlorophyll, and temperature in Moon Lake, Mississippi. Remote Sens Environ 33(2): 137148.

Ritchie JC, Schiebe FR (2000). Remote Sensing in Hydrology and Water Management, Water Quality. In: Schultz GA and Engman ET (eds.) Springer-Verlag, Berlin, Germany, 287-303, 351-352.

Running, S., Mu, Q., Zhao, M. (2017). MYD16A3 MODIS/Aqua Net Evapotranspiration Yearly L4 Global 500m SIN Grid V006 [Data set]. NASA EOSDIS Land Processes DAAC. Accessed 2020-08-26 from https://doi.org/10.5067/MODIS/MYD16A3.006

Saemian, P., Elmi, O., Vishwakarma, B. D., Tourian, M. J., \& Sneeuw, N. (2020). Analyzing the Lake Urmia restoration progress using ground-based and spaceborne observations. Science of The Total Environment, 139857.

Schulz, S., Darehshouri, S., Hassanzadeh, E., Tajrishy, M., \& Schüth, C. (2020). Climate change or irrigated agriculture-what drives the water level decline of Lake Urmia. Scientific reports, 10(1), 1-10.

Sekertekin (2020). A Survey on Global Thresholding Methods for Mapping Open Water Body Using Sentinel-2 Satellite Imagery and Normalized Difference Water Index. Arch Computat Methods Eng., https://doi.org/10.1007/s11831-020-09416-2.

Sekertekin and Bonafoni (2020). Land Surface Temperature Retrieval from Landsat 5, 7, and 8 over Rural Areas: Assessment of Different Retrieval Algorithms and Emissivity Models and Toolbox Implementation. Remote Sens. 12, 294. https://doi.org/10.3390/rs12020294.

Shadkam S, Ludwig F, van Oel P, Kirmit Ç, Kabat P (2016) Impacts of climate change and water resources development on the declining inflow into Iran's Urmia Lake. J. Great Lakes Res 42(5): 942-952. 
Singh RP, Srivastav SK (1990) Mapping of waterlogged and salt-affected soils using microwave radiometers. Int J Remote Sens 11: 1879-1887.

Srestha D., Farshad A (2009) Mapping Salinity Hazard: an Integration Application of Remote Sensing and Modeling Based Techniques, in: Zinck AJ, Mtternich G (Eds), Remote Sensing of Soil Salinization: Impact on Land Management. CRC Press. Boca Raton. 257-272.

Stanislawski, L. V., Falgout, J., \& Buttenfield, B. P. (2015). Automated extraction of natural drainage density patterns for the conterminous united states through high-performance computing. The Cartographic Journal, 52(2), 185-192.

Stone R (2015) Saving Iran's great salt lake. Sci 349(6252): 1044-1047.

Sulla-Menashe, D., \& Friedl, M. A. (2018). User guide to collection 6 MODIS land cover (MCD12Q1 and MCD12C1) product. USGS: Reston, VA, USA, 1-18.

Sulla-Menashe, D., Gray, J.M., Abercrombie, S.P. and Friedl, M.A., (2019). Hierarchical mapping of annual global land cover 2001 to present: The MODIS Collection 6 Land Cover product. Remote Sensing of Environment, 222: 183-194.

Temko, A., \& Nadeu, C. (2009). Acoustic event detection in meeting-room environments. Pattern Recognition Letters, 30(14), 1281-1288.

Tomlinson CJ, Chapman L, Thornes JE, Baker C (2011) Remote sensing land surface temperature for meteorology and climatology: a review Met Apps 18: 296-306.

Yu H, Zhang F, Kung H, Johnson VC, Bane CS, Wang J, Ren Y, Zhang Y (2017) Analysis of land cover and landscape change patterns in Ebinur Lake Wetland National Nature Reserve, China from 1972 to 2013. Wetlands 796 Ecol Manage 25(5): 619-637.

Zeinoddini M, Tofighi MA, Vafaee F (2009) Evaluation of dike-type causeway impacts on the flow and salinity regimes in Lake Urmia, Iran. J Great Lakes Res 35: 13-22.

Nourani V (2017) An emotional ANN (EANN) approach to modeling rainfall-runoff process. J Hydrol 544: $267-277$.

Legates DR, McCabe GJ (1999) Evaluating the use of "goodness-of-fit" measures in hydrologic and 